\title{
La dinámica afiliativa sindical y las trayectorias de sus miembros ${ }^{1}$
}

\author{
Ramon ALÓs \\ Centre d’Estudis Sociològics sobre la Vida Quotidiana i el Treball (QUIT) e Institut \\ d'Estudis del Treball (IET) \\ ramon.dealos@uab.cat \\ Pere JÓDAR \\ Departament de Ciències Polítiques i Socials de la Universitat Pompeu Fabra \\ pere.jodar@upf.edu \\ Pere BENEYTO \\ Universitat de València \\ Pere.J.Beneyto@uv.es \\ Sergi VIDAL \\ Universidad de Bremen \\ svidal@empas.uni-bremen.de
}

Recibido: 22-03-2013

Aceptado: 28-05-2013

Resumen: Este texto analiza la dinámica afiliativa de altas y bajas de los sindicatos españoles a partir de la ECVT (Encuesta de Calidad de Vida Laboral), y las trayectorias sindicales, esto es, el comportamiento de los afiliados desde su decisión de darse de alta en la organización, su permanencia y

${ }^{1}$ Este texto recoge los primeros resultados del Proyecto trianual de Investigación Fundamental no orientada Ref. CSO2010-17962, aprobado por el Ministerio de Ciencia e Innovación (Convocatoria 2010) y del que soy investigadora principal. Dicho Proyecto de I+D, que lleva por título La construcción política del evangelismo gitano: Iglesias, federaciones y nuevos actores políticos, cuenta con la participación formal de la Dra. Teresa San Román Espinosa, catedrática de Antropología Social de la Universidad Autónoma de Barcelona. 
participación en responsabilidades y en la acción sindical, hasta su baja; en este caso utilizando datos del registro de afiliación y desafiliación de CCOO (Comisiones Obreras) y de una encuesta a una muestra de desafiliados del mismo sindicato. El estudio realizado permite, por una parte, constatar un vínculo de continuidad entre la decisión y las motivaciones de afiliarse al sindicato, el tiempo de permanencia, el grado de implicación con la organización y los motivos que conducen a darse de baja; y por otra, identificamos cinco tipos de trayectorias sindicales, que configuran una organización compleja, que cuestiona la visión de los sindicatos como organizaciones monolíticas.

Palabras claves: afiliación, desafiliación, participación sindical, trayectoria sindical, segmentación laboral

\title{
The trade unions membership dynamics and union members' trajectories
}

\begin{abstract}
This text presents an analysis of aggregated membership's dynamics for Spanish trade unions, using ECVT data, as well as union memberships' trajectories, or members' decisions about joining the organization, permanency and responsibilities, and subsequent attrition. For the analysis of trajectories we make use of information of the records of actual memberships and the record of quitting of $\mathrm{CCOO}$, and of a survey-questionnaire to a sample of leavers of the same union. This study allows us to confirm a linkage between the decision and motivations to become union member, to participate in union activities, the time of permanency, and the motives to quit the organization. We also identify five types of union members' trajectories, indicating that, far from views that assert a monolithic structure, unions are complex organizations.
\end{abstract}

Key words: trade union membership, quitting union, union participation, union members' trajectories, labour market segmentation

\section{Referencia normalizada}

Alós, R. et. al. (2013). “La dinámica afiliativa sindical y las trayectorias de sus miembros”. Política y Sociedad, Vol.50 Núm. 3 1065-1096

Sumario: Introducción. 1.La afiliación sindical a la luz de la literatura especializada. 2.El caso español y una propuesta de análisis. 3.Datos y métodos. 4.Apunte sobre la afiliación a todos los sindicatos según la ECVT 2010. 5.La dinámica afiliativa en CCOO: una primera aproximación. 6.La dinámica afiliativa en CCOO: la desafiliación. 7.Una tipología de desafiliados. 8.Discusión y conclusiones: la teoría y la evidencia empírica contrastada en la trayectoria sindical de sus miembros. Bibliografía. 


\section{Introducción}

¿Qué trabajadores se adhieren a un sindicato y cuáles no?, ¿qué trabajadores permanecen afiliados, mientras otros tan sólo mantienen una breve experiencia sindical?, ¿qué motivos impulsan a darse de baja del sindicato?, ¿qué trabajadores participan en la acción colectiva y/o asumen responsabilidades en la organización y cuáles no, o apenas? Estos son interrogantes que han merecido, primero, una desigual atención desde la investigación especializada y, segundo, han sido abordados de forma aislada unos de otros. En este artículo pretendemos explorar una respuesta conjunta a los interrogantes planteados, entendiendo que existe un vínculo de continuidad entre los motivos que llevan a un trabajador: primero, a tomar la decisión de adherirse a un sindicato; segundo, a participar en la organización; tercero, a darse de baja de la misma. Este vínculo de continuidad lo hemos denominado trayectoria sindical. Dicha trayectoria la distinguimos de la dinámica afiliativa del sindicato que, a nuestro entender designa el número total de afiliados (o su tasa), el volumen de altas y bajas, o la fluctuación de la afiliación y su evolución en el tiempo, así como las causas que concurren.

Para responder a estos interrogantes y al objetivo genérico planteado, hemos introducido, en primer luego, la dinámica afiliativa de todos los sindicatos españoles mediante la ECVT $2010^{2}$, para luego concretar en la evolución afiliativa y las trayectorias sindicales de los afiliados a CCOO, organización de la que hemos dispuesto del registro de miembros. La investigación realizada nos aproxima al conocimiento de quiénes son los trabajadores afiliados y a los que han sido afiliados pero lo dejaron; además, concretando en CCOO, profundiza en las causas de sus altas y bajas afiliativas, así como en la adquisición de compromisos sindicales y de participación en la acción colectiva por parte de sus miembros. Debemos advertir que este análisis se ha realizado en un período en el que la crisis económica y laboral impacta en la afiliación sindical y, por tanto, los resultados aquí obtenidos ${ }^{3}$ pueden estar influenciados por la misma.

En las páginas que siguen desplegamos nuestra argumentación. Primero, repasamos la literatura especializada y presentamos el marco teórico, haciendo un énfasis especial en los efectos de la segmentación de los mercados laborales españoles en las trayectorias de afiliación. Segundo, abordamos sucintamente la metodología utilizada. En tercer lugar desarrollamos los resultados obtenidos describien-

\footnotetext{
${ }^{2}$ ECVT: Encuesta de Calidad de Vida en el Trabajo implementada por el Ministerio de Trabajo.

${ }^{3}$ En 1980, 1.109.000 asalariados estaban afiliados a los sindicatos españoles, con una tasa de afiliación del 13,7\% (Jordana, 1996). Con datos de la ECVT, en 2008, que marcó el punto álgido, los asalariados afiliados ya eran 3.361 .652 (y la tasa de afiliación del 19,8\%); el impacto de la crisis se observa en 2010, con 2.824.190 asalariados afiliados (y una tasa del 18,9\%).
} 
do la evolución de la afiliación y su fluctuación (altas y bajas), o detectamos colectivos específicos, motivaciones y práctica sindical de los miembros; también, desde una óptica explicativa, ordenamos los distintos factores para distinguir grupos diferenciados por trayectorias sindicales significativas, para terminar con un apartado de conclusiones y recomendaciones finales.

\section{La afiliación sindical a la luz de la literatura especializada}

Existe una amplia literatura y diversidad de enfoques que explican los factores que inciden sobre la dinámica afiliativa de los sindicatos. Desde una perspectiva macro o general diversos autores analizan ya sea el aumento, ya sea la reducción, del volumen y la tasa de afiliación sindical. Así, desde el estudio de Bain y Elsheikh (1976) se constata que diversas variables macroeconómicas y del mercado de trabajo (variación del empleo, paro, salarios, precios, PIB, estructura sectorial, estructura empresarial, importancia relativa del sector público), así como factores políticos e institucionales (orientación política del gobierno, modelo de relaciones laborales, estructura de la negociación colectiva, legislación laboral, protección frente al desempleo) inciden en la variación del volumen (y, en su caso, tasa) de afiliación sindical (Guest y Dewe, 1988; Western, 1997; Ebbinghaus y Visser, 1998; Ferner y Hyman, 1998; Scruggs y Lange, 2001; Calmfors et al., 2002; Checchi y Lucifora, 2002; Bryson y Gomez, 2005; Brady, 2007; Pedersini, 2010).

Desde una perspectiva micro, se analizan los factores que inciden en la propensión a la afiliación sindical; es decir, qué tipo de trabajadores constituye la base más amplia de adscripción al sindicato. Las respuestas recaen en variables socio demográficas (edad, sexo, estudios, origen); en variables laborales y empresariales (plantilla de la empresa, sector de actividad, contrato de trabajo, antigüedad en la empresa, ocupación); también de orden cultural (valores más individualistas o cooperativos, materialistas o post materialistas, proximidad o lejanía hacia lo que representa el sindicato, significado personal de profesión y de trabajo). Los estudios realizados resaltan tres grandes interpretaciones: las instrumentales, fundamentadas en la teoría de la acción colectiva de Olson (1992) y el rational choice. Las basadas en los niveles de satisfacción-insatisfacción en el trabajo (Freeman y Medoff, 1984; Barling et al., 1992; Friedman et al., 2006), o en la predisposición a la integración en la organización (Visser, 1995; Allvin y Sverke, 2000; Cregan, 2005; Blanchflower, 2007; Checchi et al., 2010). Y, por último, las que se remiten a factores externos, como el papel de las instituciones sociales y del proceso de trabajo en cuanto proveedores de oportunidades o de restricciones a la participación (Klandermans, 2002; Kuruvilla et al., 1990; Newton y Shore, 1992; Gallagher y Clark, 2001; Blackwood et al., 2003). En el seno de las dos últimas interpretaciones también se han analizado las predisposiciones y oportunidades de jóvenes (Gomez et al., 2004; Haynes et al., 2005; Waddington y Kerr, 2002), mujeres (Tomlinson, 2005; Kirton, 2005; Sinclair, 1996; Sudano, 1998), o inmigrantes (Turner et al, 2007; Wrench, 2004). A todo ello hay que añadir las variables de presencia sindical y de trabajado- 
res o compañeros afiliados en el centro de trabajo (teoría social custom; Checchi y Visser, 2005; Schnabel y Wagner, 2007).

No obstante, las cifras y tasas de adscripción pueden variar, asimismo, por factores propios de la organización sindical, ya que su dinámica afiliativa no depende sólo de reclutar nuevos miembros, sino también de conservar los actuales. Sin embargo, se dispone de pocos estudios sobre los motivos de por qué un trabajador ya afiliado a un sindicato se da de baja del mismo y es aquí donde en mayor medida se centra la investigación que presentamos. Cuando se trata de la salida orgánica, se suele analizar si la decisión de darse de baja recae exclusivamente en el sindicato (desacuerdo ideológico, con su actuación o con alguno de sus representantes, coste de la cuota, insatisfacción con algún servicio o con el trato recibido); pero nuevamente no se agotan ahí todas las posibilidades y la literatura pone sobre la mesa factores de orden laboral (pérdida o cambio de empleo, jubilación, traslado, actitud de las empresas), o de orden personal y familiar (Klandermans, 1986; Gallie, 1996; Waddington y Kerr, 1999; Visser, 2002; Guest y Conway, 2004; Oesch, 2012) y, naturalmente se pueden concatenar causas de estos diferentes órdenes.

Para el caso de España, de forma hasta cierto punto complementaria, los estudios de Rodríguez (1996), Simón (2003), Beneyto (2004, 2008, 2011a), Alós et al. (2000), Llorente (2007), Jódar et al. (2009a y 2009b -este último incluye motivos de desafiliación) constatan que en la afiliación sindical influyen variables: sociodemográficas como sexo, edad, origen, nivel de estudios, origen social, ideología; laborales como sector de actividad, empleo o actividad desarrollada, plantilla del centro de trabajo, empleador público o privado, contrato de trabajo, salario, antigüedad en la empresa, tipo de jornada de trabajo; $y$, también, sindicales como presencia sindical en el centro de trabajo, y su capacidad de movilización y convocatoria.

\section{El caso español y una propuesta de análisis}

En este estado de la cuestión debe destacarse la carencia de análisis del conjunto de cuestiones que inciden en la dinámica afiliativa de los sindicatos (Schnabel, 2003); es decir que abarquen el estudio de quiénes son los miembros (base afiliativa), quiénes los que se dan de alta a lo largo de un periodo, quiénes participan en actividades y asumen responsabilidades organizativas y de representación, quiénes se mantienen comprometidos con la organización o, contrariamente, quiénes se dan de baja de la misma; acompañado todo ello por los motivos que explican unas y otras decisiones. Para poner un ejemplo de la importancia que puede suponer entender la dinámica afiliativa del sindicato basten los siguientes datos, que extraemos del estudio que origina este texto (Alós et al., 2011: 33): para España, los jóvenes de hasta 29 años representaron el 8,1\% de los afiliados a CCOO a finales del año 2010; y, sin embargo, fueron el 69,9\% de las altas habidas al mismo sindicato en el transcurso del año 2010, contrapesadas por representar, asimismo, el 58,9\% de las bajas a lo largo del mismo año. En este sentido, nuestra propuesta pretende avanzar en un análisis armonizado de la dinámica afiliativa; para ello debemos incluir, sin descui- 
dar factores contextuales, las trayectorias sindicales de los miembros observadas en el interior de la organización.

El presupuesto inicial es la existencia de una pluralidad de trayectorias sindicales. Así, una parte de la literatura especializada permite apuntar que el mercado de trabajo puede ser un factor discriminante de las trayectorias sindicales; especialmente relevante en el caso español, con una tasa de paro del 20,3\% y una tasa de temporalidad del 24,8\%, según la Encuesta de Población Activa (EPA) del cuarto trimestre de 2010 -período de realización del estudio-. Como han fundamentado Prieto et al. (2009), las estrategias empresariales inciden en la segmentación laboral de los asalariados en España, dando lugar a significativas diferencias en condiciones de trabajo (y calidad del empleo). En un sentido similar, Lorenz y Valeyre (2005) ya revelaban una asociación fuerte entre estilos de gestión de mano de obra que potencian la autonomía y la responsabilización de los trabajadores, con mayor cualificación de los asalariados y menor precariedad del mercado de trabajo; y, en sentido contrario, entre estilos de gestión taylorista, rutinarios y jerárquicos, asociados a menor cualificación y mayor precariedad del mercado de trabajo o a bajos salarios. A todo ello hay que añadir el contexto institucional. Por una parte, la legislación que regula la representación y la negociación colectiva de los trabajadores confiere al sistema de relaciones laborales español una orientación inclusiva (voz y beneficios erga omnes), lo que reduce el papel de los incentivos instrumentales en la afiliación (Baylos, 1999; Valdés dal Re, 1996; Beneyto, 2011a y 2011b; Jódar et al., 2011a). Pero, por otra parte, la legislación laboral y, como apunta Toharia (2011), las sucesivas reformas impulsadas desde gobiernos de distinto signo, han contribuido a la segmentación del mercado de trabajo, generando fuertes desigualdades (Recio, 1999, 2005; Banyuls et al., 2009; Prieto et al., 2009). La aplicación de las reformas ha incentivado el uso empresarial de técnicas de gestión de personal intensivas en mano de obra que prima la precariedad o el bajo salario. Tampoco debe olvidarse, dado el marco presentado, que las prácticas sindicales de acción y de representación, o de distribución de recursos y capacidad de convocatoria y movilización, pese a sus propósitos universalistas, pueden contribuir también a la segmentación del mercado de trabajo (Alós, 2008).

Así por ejemplo, un trabajador central, con empleo fijo y en una empresa o centro de trabajo de ciertas dimensiones, puede ver favorecido su compromiso sindical, en comparación con el trabajador periférico, con empleo inestable y en pequeña empresa (Kochan et al., 1993; Hyman, 1994; Miguélez, 1999; Booth et al., 2000; Fernández, 2002; Llorente, 2007). Justamente, hace un tiempo Dubois (1976) señalaba que la acción colectiva de los asalariados requiere dos condiciones básicas: estabilidad en el empleo y relativa homogeneidad interna de la fuerza de trabajo. A ello cabe añadir otros aspectos que influyen en la afiliación (Lange y Ross, 1991; Labbé y Croisat, 1992), relacionados con las propensiones individuales como, por ejemplo: tener una queja o problema que el sindicato puede resolver (afiliación instrumental); compartir los valores que defiende el sindicato (adscripción identitaria); ser miembro de un grupo de afinidad, ayudado por la antigüedad en el empleo y la presencia del sindicato en el centro de trabajo (la socialización como factor de 
afiliación). Como apunta Visser (2002), los trabajadores centrales tienen mayores oportunidades de afiliación y de participación sindical, mientras que, comparativamente, los trabajadores periféricos obtienen menores beneficios y mayores costes derivados de la adscripción. Pero cabe añadir otros factores que inciden en las trayectorias sindicales; por ejemplo, los más jóvenes posiblemente están más interesados en su inserción en el mercado de trabajo que en mejorar las condiciones de su actual empleo (Antón, 2007; Miguélez y Recio, 2009; Germe, 2011); o para muchos inmigrantes acrecentar sus perspectivas laborales se sitúa más en el cambio de empleo o de empresa que en la acción colectiva o sindical (Jódar et al., 2011c). Sin olvidar, como muestran Calderón y López Calle (2010), que el tipo de empleo en sí mismo genera actitudes y lógicas de comportamiento divergentes entre trabajadores estables y trabajadores precarios.

Estos retos y complejidades son interpretadas, en determinados círculos, atribuyendo la segmentación de los mercados de trabajo a los propios trabajadores centrales y 'sus' organizaciones que limitan el acceso a los asalariados periféricos. Pero no olvidemos que el enfoque de la segmentación (Doeringer y Piore, 1983; Piore, 1983) surge en Estados Unidos como una explicación del comportamiento de las empresas, por incumplir éstas los presupuestos neoclásicos, generando interesadamente una dualidad que les permite controlar mejor el factor trabajo y su precio.

Nuestra hipótesis principal es que la trayectoria sindical (afiliación, compromiso, tiempo de permanencia) se relaciona con la situación de empleo. Pero, no planteamos la existencia de una relación de causalidad, sino una interacción o asociación entre ambas que finalmente explica los motivos de desafiliación (ver esquema 1). De forma resumida, distinguimos las trayectorias sindicales de unos trabajadores afiliados- centrales, que constituyen el núcleo amplio de los miembros del sindicato; Hyman (2004) señala que, en sus filas, están los miembros que adquieren compromisos organizativos y de representación en los centros de trabajo; o sea, una afiliación estable en el tiempo, que se da de baja cuando alcanza la jubilación (Labbé y Croisat, 1992), también por reducciones de plantilla o cierre de empresa y, asimismo, por desacuerdo o insatisfacción con la política sindical. Frente a ellas se contraponen las trayectorias sindicales de los trabajadores periféricos que constituyen un segmento menor en términos cuantitativos en el conjunto afiliativo, y que no suelen adquirir compromisos, en su breve permanencia, dándose de baja por finalización de contrato, cambio de empresa, paro, o bien por no necesitar el servicio sindical que les impulsó a darse de alta (ver: Visser 2002, Lévesque et al., 2005; Waddington, 2006; Jódar et al., 2011b); su tasa de afiliación es más reducida en contraste con la proporción de los miembros centrales.

Estas características diferenciadas esperamos que se relacionen con las motivaciones de unos y otros, en un momento crítico como es el de dejar de ser miembros de la organización. Por ello, aunque nuestro punto de partida es dual, planteamos una segunda hipótesis de carácter exploratorio según la cual esperamos que tanto entre las trayectorias sindicales y motivaciones de desafiliación de los afiliados centrales, como entre las de los periféricos, aparezcan nuevos itinerarios al introducir motivaciones, valores y actitudes, así como otras características personales y 
laborales. Ello permitiría dar base a una tipología más amplia (segmentada) de trayectorias afiliativas sindicales.

Esquema 1. Trayectoria sindical según situación de empleo

\begin{tabular}{|c|c|c|c|c|}
\hline & $\begin{array}{c}\text { Motivo afilia- } \\
\text { ción }\end{array}$ & $\begin{array}{c}\text { Compromiso } \\
\text { sindical }\end{array}$ & $\begin{array}{c}\text { Permanencia en } \\
\text { la organización }\end{array}$ & Desafiliación \\
\hline $\begin{array}{c}\text { Trabajador } \\
\text {-afiliado- } \\
\text { central }\end{array}$ & $\begin{array}{c}\text { Socialización, } \\
\text { identidad, mejora } \\
\text { condiciones } \\
\text { empleo }\end{array}$ & $\begin{array}{c}\text { Alto: militantes } \\
\text { y cuadros del } \\
\text { sindicato }\end{array}$ & Elevada & $\begin{array}{c}\text { Por jubilación, } \\
\text { cierre empresa o } \\
\text { discrepancia } \\
\text { ideológica }\end{array}$ \\
\hline $\begin{array}{c}\text { Trabajador } \\
\text {-afiliado- } \\
\text { periférico }\end{array}$ & $\begin{array}{c}\text { Protección ante } \\
\text { empresa, servi- } \\
\text { cios de asesora- } \\
\text { miento }\end{array}$ & Escaso & $\begin{array}{c}\text { Breve o muy } \\
\text { breve }\end{array}$ & $\begin{array}{c}\text { Por causas labora- } \\
\text { les o finalización } \\
\text { del servicio sindical }\end{array}$ \\
\hline
\end{tabular}

Fuente: elaboración propia.

\section{Datos y métodos}

Como ya se ha comentado, partimos de dos fuentes principales de datos, unos generales extraídos de la ECVT $2010^{4}$ y otros específicos del sindicato CCOO. En referencia a la ECVT de 2010, la hemos limitado al 81,4\% de la muestra correspondiente a los ocupados asalariados, dejando fuera a empresarios, autónomos y ayuda familiar, colectivos ajenos a la acción y la afiliación sindical tradicional.

Por lo que se refiere a los datos de CCOO de España, son tres las fuentes utilizadas. El registro de desafiliación incorpora a todos los trabajadores afiliados que han sido baja del sindicato en los primeros diez meses del año 2009, esto es, un total de 160.376 individuos. La información incluye: fecha de nacimiento, sexo, país de nacimiento, fecha del alta al sindicato, vía de acceso a la afiliación, tipo de cuota pagada, federación de adscripción, comunidad autónoma, número de afiliados en la empresa y sector de actividad. El registro de afiliación con los datos del conjunto de

\footnotetext{
${ }^{4}$ La ECVT es una encuesta de carácter nacional que incluye una pregunta sobre la afiliación sindical de los ocupados. Su objetivo es investigar la calidad de vida que tiene el ocupado en su trabajo mediante, por una parte, información sobre las situaciones y actividades que se producen en su entorno de trabajo y en su entorno familiar y, por otra, recabando las percepciones personales que los trabajadores ocupados tienen de sus condiciones y relaciones laborales. Se elabora mediante una muestra trietapica de 9240 ocupados residentes en viviendas familiares principales de todo el territorio español, tomando como referencia el Padrón Continuo. Los datos de afiliación sindical son totales, no se puede distinguir por sindicatos; aunque sí entre actualmente afiliado, afiliado anteriormente y nunca afiliado.
} 
afiliados al sindicato en octubre de 2009 (1.203.309), dichas variables son idénticas a las del registro de desafiliación. La tercera fuente es una encuesta representativa del conjunto de los desafiliados, con base a una muestra estratificada de 1000 miembros que se han dado de baja en $2009^{5}$ (más detalles en Alós et al., 2011:10).

Para los análisis hemos recurrido ante todo a tablas de contingencia, que ofrecen una primera descripción, complementada con el análisis de regresión logística y el análisis factorial de correspondencias múltiples. El análisis de regresión permite evaluar el grado de influencia sobre una variable dependiente de una variable explicativa controlando por los efectos indirectos de otras y, con ello, se ha contrastado la primera hipótesis. Por su parte, el análisis factorial propuesto discrimina a los individuos por proximidad o distancia en relación con algunos atributos relevantes obteniéndose unas pocas dimensiones que sintetizan estas distancias; $y$, a partir de las diferencias observadas, el análisis de clúster clasifica a la población de la muestra en diferentes grupos según la homogeneidad de sus características; lo que nos ha permitido profundizar en la segunda hipótesis y proponer una tipología de desafiliados.

\section{Apunte sobre la afiliación a todos los sindicatos según la ecvt 2010}

La distancia entre afiliados y no afiliados para el conjunto de los sindicatos españoles (Beneyto (2008, 2011a; Alós et al., 2011) no sólo responde a características individuales (edad, estudios, tipo de ocupación, etc.), sino también de contexto (sector, actividad, tamaño de empresa) e institucionales (presencia del sindicato, influencia de la negociación colectiva). En la tabla 1 (con datos ECVT 2010) se aprecian los rasgos del conjunto de miembros de todos los sindicatos españoles, más cercanos al segmento primario o central de los asalariados; mientras que los segmentos secundarios ven obstaculizado su acceso a las organizaciones sindicales, primero por la inestabilidad de su trayectoria laboral y, después, por su ubicación en determinados sectores de actividad, empresas y tipos de ocupación.

La tabla 2, también con base a datos de la ECVT, nos permite observar la desigual influencia, conocimiento y repercusión de la acción sindical por parte de diversos colectivos de trabajadores. Así, los afiliados que trabajan en empresas con representantes elegidos por los trabajadores, también tienen más cobertura por convenio colectivo o similar, o mayor conocimiento de la actividad sindical y, por

${ }^{5}$ La encuesta de las bajas de CCOO se realizó con base a una muestra representativa de 1000 desafiliados, estratificada por sexo, edad y federación y substituciones programadas. La entrevista ha sido telefónica nominal, realizándose a lo largo del mes de junio de 2010, mediante una empresa especializada. El margen de error para los resultados globales es de $\pm 3,20$ puntos en el caso de máxima indeterminación $(\mathrm{p}=\mathrm{q})$ y con un intervalo de confianza del 95,5\%. 
ello, valoran mejor diversos aspectos de la misma, en particular la representación y defensa de sus intereses. Los ex afiliados, al conjunto de sindicatos, asimismo conocen la actividad sindical, aunque su valoración es más negativa. Por su parte, los nunca afiliados se concentran proporcionalmente más en empresas sin representantes sindicales, o lo desconocen, y disponen de menor cobertura derivada de la negociación colectiva; de ahí que apenas tengan conocimiento de la actividad sindical, y cuando lo tienen, su valoración es baja, aunque por encima de la sostenida por los ex afiliados. La situación contractual permite observar el menor conocimiento de la actividad sindical de los asalariados temporales; aunque, en comparación con los fijos, su valoración de las funciones sindicales sólo es algo menor. Finalmente, destaca la baja valoración en cuanto a beneficios laborales que merece para todos los colectivos el hecho de estar afiliado; quizás debido al carácter inclusivo del sistema de relaciones laborales español. Esta breve descripción permite apuntar que la acción colectiva de los trabajadores no sólo depende de decisiones sindicales, sino también del contexto laboral o de las prácticas de gestión de personal de las empresas

Tabla 1. Tasa de afiliación y de bajas al conjunto de sindicatos españoles. ECVT 2010

\begin{tabular}{|c|l|c|c|}
\hline & \multicolumn{2}{|c|}{$\begin{array}{c}\text { Tasa de afilia- } \\
\text { ción (\%) }\end{array}$} & $\begin{array}{c}\text { Tasa de } \\
\text { bajas (\%) }\end{array}$ \\
\hline \multicolumn{1}{|c|}{$\begin{array}{c}\text { Hombres } \\
\text { VAujeres }\end{array}$} & 20,6 & 11,6 \\
\hline Sexo & \multicolumn{1}{|c|}{16,8} & 8,9 \\
\hline \multirow{5}{*}{ Edad } & De 16 a 24 años & 7,1 & 0,6 \\
& De 25 a 34 & 13,4 & 5,6 \\
& De 35 a 44 & 19,2 & 8,7 \\
& De 45 a 54 & 25,3 & 6,7 \\
& De 55 a 64 & 24,6 & 20,6 \\
& De 65 y más años & 18,9 & 13,1 \\
\hline Nacionalidad & Española & 20,3 & 11,1 \\
& Extranjera & 6,6 & 4,6 \\
\hline \multirow{5}{*}{ Nivel de estudios } & 17,3 & 13,7 \\
& Primarios & 16,6 & 10,4 \\
& Secundarios-I & 20,6 & 10,5 \\
& Secundarios-II & 20,5 & 8,7 \\
& Universitarios & \multicolumn{2}{c|}{} \\
\hline VARIABLES OCUPACIONALES & 10,1 & 6,4 \\
\hline \multirow{3}{*}{ Ocupación } & Directivos & 21,2 & 9,4 \\
& Técnicos y profesionales & 21,9 & 11,7 \\
& Administrativos & 17,1 & 12,0 \\
& Trabajadores cualificados & 18,4 & 9,5 \\
\hline
\end{tabular}




\begin{tabular}{|c|c|c|c|}
\hline & & $\begin{array}{c}\text { Tasa de afilia- } \\
\text { ción (\%) }\end{array}$ & $\begin{array}{c}\text { Tasa de } \\
\text { bajas (\%) }\end{array}$ \\
\hline \multirow{9}{*}{ Actividad } & Agricultura & 8,1 & 9,0 \\
\hline & Industria & 22,4 & 10,8 \\
\hline & Construcción & 12,2 & 12,9 \\
\hline & Comercio y Hostelería & 10,9 & 9,4 \\
\hline & Transporte y comunicaciones & 23,6 & 9,9 \\
\hline & Servicios financieros & 26,6 & 7,9 \\
\hline & Servicios empresariales & 13,6 & 8,1 \\
\hline & Servicios públicos & 28,0 & 12,2 \\
\hline & Serv. personales y a la comunidad & 8,0 & 7,8 \\
\hline \multirow{4}{*}{ Tamaño de la empresa } & De 1 a 9 trabajadores & 11,3 & 9,3 \\
\hline & De 10 a 49 & 20,2 & 10,1 \\
\hline & De 50 a 249 & 24,1 & 12,1 \\
\hline & De 250 y más & 30,3 & 11,8 \\
\hline \multicolumn{4}{|c|}{ VARIABLES CONTRACTUALES } \\
\hline \multirow[t]{2}{*}{ Tipo de contrato } & Indefinido & 21,2 & 10,9 \\
\hline & Temporal & 11,7 & 8,9 \\
\hline \multirow[t]{2}{*}{ Tipo de jornada } & Completa & 19,5 & 10,9 \\
\hline & Parcial & 14,9 & 7,0 \\
\hline \multirow[t]{2}{*}{ Sector } & Privado & 15,5 & 10,0 \\
\hline & Público & 28,0 & 11,6 \\
\hline \multirow{4}{*}{$\begin{array}{l}\text { Antigüedad en la } \\
\text { empresa }\end{array}$} & Menos de 1 año & 7,0 & 8,8 \\
\hline & De 1 a 3 años & 13,4 & 7,7 \\
\hline & De 3 a 10 años & 15,5 & 11,2 \\
\hline & Más de 10 años & 29,9 & 11,9 \\
\hline \multirow{4}{*}{ Salario } & Hasta $1.000 €$ & 10,7 & 8,8 \\
\hline & De 1001 a 1600 & 20,2 & 10,9 \\
\hline & De 1601 a 2100 & 30,4 & 12,2 \\
\hline & Más de $2100 €$ & 22,5 & 10,2 \\
\hline \multirow{4}{*}{$\begin{array}{l}\text { Representación sindi- } \\
\text { cal en la empresa }\end{array}$} & $\mathrm{Si}$ & 30,0 & 8,5 \\
\hline & No & 9,6 & 12,3 \\
\hline & No sabe & 6,9 & 10,1 \\
\hline & TOTAL & 18,9 & 10,4 \\
\hline
\end{tabular}

Nota: tasa de bajas indica la proporción de asalariados ocupados que han sido afiliados a algún sindicato del que se han dado de baja sin ser alta en otro.

Fuente: elaboración propia con datos de la ECVT 2010. 
Tabla 2. Conocimiento y valoración de los sindicatos, según ECVT 2010. Puntuación media obtenida según colectivos (escala de $0=$ nulo a $10=$ máximo)

\begin{tabular}{|l|c|c|c|c|}
\hline & $\begin{array}{c}\text { Conocimiento de } \\
\text { la actividad } \\
\text { sindical }\end{array}$ & $\begin{array}{c}\text { Valoración } \\
\text { representación } \\
\text { y defensa de } \\
\text { sus intereses } \\
\text { por sindicatos }\end{array}$ & $\begin{array}{c}\text { Valoración } \\
\text { beneficios } \\
\text { laborales por } \\
\text { estar afiliado }\end{array}$ & $\begin{array}{c}\text { Valoración } \\
\text { beneficios } \\
\text { laborales } \\
\text { obtenidos por } \\
\text { sindicatos en su } \\
\text { empresa }\end{array}$ \\
\hline Afiliados & $5,77(2,55)$ & $5,71(2,41)$ & $3,95(3,14)$ & $4,76(2,93)$ \\
\hline Ex afiliados & $4,56(3,10)$ & $4,06(2,62)$ & $2,95(2,80)$ & $3,62(2,96)$ \\
\hline Nunca afiliados & $2,56(2,97)$ & $4,34(2,60)$ & $3,79(2,85)$ & $4,06(2,71)$ \\
\hline $\begin{array}{l}\text { Asalariados } \\
\text { fijos }\end{array}$ & $3,63(3,21)$ & $4,79(2,63)$ & $3,76(3,02)$ & $4,28(2,89)$ \\
\hline $\begin{array}{l}\text { Asalariados } \\
\text { temporales }\end{array}$ & $2,61(3,01)$ & $4,63(2,62)$ & $3,66(2,82)$ & $4,11(2,66)$ \\
\hline
\end{tabular}

Nota: entre paréntesis la desviación estándar.

Fuente: elaboración propia con datos de la ECVT 2010.

\section{La dinámica afiliativa en ccoo: una primera aproximación}

En referencia a la dinámica afiliativa, la tabla 3 muestra la importancia de la fluctuación (altas y bajas) para el caso de CCOO, así como los agudos efectos de la crisis económica en la misma. Pero la fluctuación no afecta por igual a la composición de la base afiliativa del sindicato, pues pese a que las altas en el año 2010 representan el 11,3\% de la misma y las bajas el 15,9\%, de hecho, el 24\% de los que se dan de baja lleva menos de un año afiliado; es decir, se trata de una afiliación puntual, de breve duración, posiblemente en torno al asesoramiento o el uso de un servicio sindical.

Tabla 3. Datos básicos de la dinámica de afiliación a CCOO, de 2007 a 2010

\begin{tabular}{lcccc}
\hline \multicolumn{1}{c}{ CCOO } & 2007 & 2008 & 2009 & 2010 \\
\hline Afiliación (31/12 de cada año) & 1.141 .321 & 1.201 .520 & 1.203 .309 & 1.171 .860 \\
Altas & 167.551 & 185.084 & 168.578 & 132.666 \\
Bajas & 132.417 & 150.133 & 191.127 & 186.127 \\
Saldo afiliativo & 57.402 & 60.199 & 1.789 & -46.539 \\
\hline Tasa de altas & $14,7 \%$ & $15,4 \%$ & $14,0 \%$ & $11,3 \%$ \\
Tasa de bajas & $9,7 \%$ & $10,4 \%$ & $13,9 \%$ & $15,9 \%$ \\
Fluctuación & $24,4 \%$ & $25,8 \%$ & $27,9 \%$ & $27,2 \%$ \\
Tasa de crecimiento & $5,0 \%$ & $5,0 \%$ & $0,1 \%$ & $-4,6 \%$ \\
\hline
\end{tabular}

Fuente: elaboración propia con datos de la Secretaria de Afiliación de CCOO, Informe de afiliación comparativo. 
En este panorama de transformación se ha avanzado en la adaptación del sindicato $\mathrm{CCOO}$ a la sociedad post-industrial y, aunque el registro tiene pocas variables para comparar con la muestra ECVT, se observa el crecimiento de los afiliados del sector servicios en relación con los de la industria (la afiliación de servicios en 1981 era el 25,9\% y el 64,3\% en 2010); también los del sector público (13,3\% en 1981 y $21,5 \%$ en 2010). Asimismo se ha constatado que el sindicato afilia también a las mujeres (del 32,4\% de la afiliación en 2000 al 38,8\% en 2010) y a segmentos de mayor nivel educativo y profesional. Sin embargo, otros rasgos significativos de la afiliación han variado poco en el tiempo, como su concentración entre trabajadores con contrato indefinido y con antigüedad dilatada en empresas de gran dimensión. Con todo, puede concluirse que el sindicalismo español ha sido más dinámico y adaptable de lo que argumentan sus críticos (p.e., Dolado et al., 2010); no sólo ha aumentado en afiliación, sino también en representatividad de segmentos diferenciados de trabajadores, alcanzando sectores de cuello blanco y de servicios antes estancos a la sindicalización. Ahora bien, el contexto cuenta; así, allá donde el sindicato dispone de representación institucionalizada (comité de empresa, sección sindical) y puede desplegar de forma eficaz su actividad (sobre todo en medianas y grandes empresas, en la función pública) la tasa de afiliación es considerablemente más alta y, además, suele ser más estable la permanencia en el sindicato, o mayor la participación en sus actividades (Jódar et al., 2011a).

En sentido contrario, algunos grupos y colectivos sociales presentan menores niveles de afiliación, como los jóvenes (menores de 30 años: 8,1\% de la afiliación a CCOO en 2010) y los inmigrantes (0,4\% del total de la afiliación a CCOO en 2000 y 5,1\% en 2010), sobre todo los extracomunitarios. Del mismo modo, tal y como se observa en la tabla 1, con datos ECVT para el conjunto de los sindicatos, también en $\mathrm{CCOO}$ se detectan dificultades para afiliar y retener a los trabajadores desocupados, a los temporales, a los asalariados de la pequeña empresa y de los sectores más dispersos y propensos a la precarización, como agricultura, construcción, comercio, hostelería o servicios personales; también es más difícil que permanezcan en la organización los asalariados más inestables y con poca antigüedad en la empresa, o con menor nivel de estudios (véase al respecto Beneyto, 2008 y 2011a; Köhler y Calleja, 2011). Ahora bien, se percibe que una buena parte de los colectivos que más se desafilian, son también los que más crecen dentro del sindicato (Jódar et al., 2009b). Es el caso de las mujeres que, de forma lenta pero sostenida, reducen diferencias con los hombres; o, asimismo y hasta la crisis, el de los inmigrantes que aumentaron su presencia de forma significativa.

\section{La dinámica afiliativa en ccoo: la desafiliación}

Un rasgo neto de la dinámica afiliativa de los sindicatos españoles, tal y como hemos descrito, es su fluctuación; en este apartado acometemos uno de sus extremos: las bajas sindicales. En el esquema 2 recogemos las características más sobresalientes de la muestra de desafiliados de CCOO, que dan cuenta de una primera 
cuestión: ¿quiénes se desafilian? Como se puede observar, las características demográficas y ocupacionales de los desafiliados se distribuyen de manera que están presentes de manera aleatoria los dos grupos polarizados: centrales (hombres maduros de la industria, por ejemplo) y periféricos (mujeres y hombres jóvenes de servicios de baja cualificación). No obstante, cuando nos detenemos en las variables sindicales -tercera columna- la segmentación adquiere un cierto orden (las dos facetas remarcadas), tanto por lo que respecta a la antigüedad o permanencia afiliativa, como a algunas de sus características ocupacionales (estables, no estables), también en la duración de la afiliación y los motivos y medios mediante los que se afilian. La variación según características de las bajas afiliativas a CCOO, sigue una pauta similar a la que ofrece la ECVT, para el conjunto de los sindicatos españoles.

Esquema 2. Principales características de los desafiliados/as de CCOO

\section{Demográficas}

Casados, con hijos.

Edad media 41,4 años.

Estudios primarios $\mathrm{y}$ secundarios

Mujeres:

Administrativas, comercio, servicios

Hombres:

Cualificados, jefes y mandos intermedios, técnicos, profesionales (30-44 años)

No cualificados $(+45$ años) y temporales.
Ocupacionales

$50 \%$ sin empleo: $34 \%$ en paro, $13 \%$ jubilado

$50 \%$ ocupado:

$35 \%$ indefinido

$63 \%$ de servicios

$21 \%$ de industria

15\% construcción

$12 \%$ comercio

7\% administración pública

Antigüedad empresa:

Más antigüedad: jubilados

Menos antigüedad: paro, contrato temporal.

Paro y contrato temporal; más cambios de empresa

$40 \%$ pequeños centros de

trabajo

$12 \%$ centros de +500 trabaja-

dores.
Sindicales

Dos facetas de la permanencia 1. Afiliación breve ( $<2$ años); paro y temporales; más inmigrantes.

2. Afiliación dilatada (>10 años); pensionistas y jubilados

La estabilidad en la empresa, requisito de afiliación; a menor antigüedad más riesgo de desafiliación

1. Afiliación breve ( $<2$ años): afiliados por iniciativa propia en local del sindicato (pequeña empresa)

2. Afiliación dilatada (>10 años): afiliados por medio de delegado o sindicalista (gran empresa).

Fuente: elaboración propia con datos de la encuesta CCOO a desafiliados 2009. 
Para explorar las dos facetas mencionadas en el esquema 2 necesitamos conocer los motivos de baja que sólo nos ofrece la encuesta específica realizada a CCOO. Según la tabla 4, los motivos de baja no sindicales (el 51,3\%), aventajan ligeramente las causas sindicales $(48,7 \%)$. Entre los motivos de contexto, destacan los laborales $(84,2 \%$ de las causas externas) muy por encima de los personales y otros motivos (12,3\% y 3,5\% de factores no sindicales, respectivamente). Ahora bien, entre las motivaciones laborales hemos de destacar, por un lado todas aquellas que están relacionadas con el paro -las 2/3 partes-, seguidas de la jubilación o prejubilación y, finalmente, otros cambios de situación ocupacional (de empleo o de empresa, traslado,...). Entre los motivos sindicales, hemos distinguido principalmente dos: los económicos o instrumentales (utilidad, necesidad, servicios, coste de la cuota) que representan el $57 \%$ de las causas sindicales de baja, y los motivos de desacuerdo o insatisfacción (con objetivos, ideas o formas de acción) que aducen el $43 \%$ de los que se han desafiliado.

Tabla 4. Distribución de los desafiliados según principal motivo de desafiliación

\begin{tabular}{ll} 
No le ve utilidad al sindicato o la cuota es cara & $17,7 \%$ \\
Disconforme con actuación del sindicato o miembros & $16,4 \%$ \\
Disconforme con el funcionamiento del sindicato o coste servicios & $10,1 \%$ \\
Se ha afiliado a otro sindicato & $4,5 \%$ \\
Total motivos sindicales & $\mathbf{4 8 , 7 \%}$ \\
Cambio de situación laboral & $43,2 \%$ \\
Motivos personales & $6,3 \%$ \\
Otros motivos & $1,8 \%$ \\
Total motivos no sindicales & $\mathbf{5 1 , 3 \%}$ \\
Total (N=1.000) & $100 \%$ \\
\hline
\end{tabular}

Fuente: elaboración propia con datos de la encuesta CCOO a desafiliados 2009.

Una vez delimitadas y jerarquizadas las motivaciones de baja, podemos relacionar las causas de salida del sindicato y la segmentación detectadas anteriormente entre los desafiliados. Entre los datos obtenidos (ver Alós et al., 2011) destaca que, comparativamente, son una parte de los afiliados (o ex afiliados) con características centrales (mayor nivel de estudios, cualificación, servicios más regulados) los que en mayor medida dejan el sindicato por desacuerdo o insatisfacción con la organización; mientras entre los que aducen motivos laborales o personales, encontramos tanto afiliados centrales, como periféricos, a los que sobre todo les separa la edad, aunque les une la menor cualificación y nivel de estudios, así como la ocupación manual. Pero no olvidemos que la dinámica afiliativa se caracteriza por ser de doble dirección entre sindicato e inscritos; en este caso entre CCOO y los incentivos y actitudes de los desafiliados hacia sus representantes. Así, la mayor parte de los desafiliados llegaron al sindicato por motivos de defensa y protección frente a la empresa (44\%), o para obtener asesoramiento jurídico y laboral (39\%). Pero tam- 
bién hay un núcleo más reducido que valora los incentivos sociales (28\%) e identitarios (30\%), así como quien aspira a mejorar su salario y condiciones de trabajo (31\%). Del mismo modo, si bien la opinión general no es muy positiva, hay un 44,5\% de los desafiliados que sostienen que, en gran medida, el sindicato resuelve problemas de trabajo, o que tienen confianza en los sindicalistas de la empresa $(44,8 \%)$, incluso en los sindicalistas de fuera de la empresa (38,1\%). Y aquí, nuevamente, surgen diferencias de valoración entre los miembros que han causado baja, según características demográficas, ocupacionales y sindicales.

La valoración del sindicato también se relaciona con el grado de participación que han mantenido los ahora desafiliados (ver Alós et al., 2011). Así, los que se han jubilado o prejubilado valoran más el sindicato y han sido altamente participativos mientras han estado afiliados. También las mujeres y los que están en paro valoran mejor la acción del sindicato, pero junto a los jóvenes, los temporales, los que trabajan en la pequeña empresa, o un sector tan propenso a la dispersión como hostelería y comercio, han sido poco participativos en su, normalmente breve, estancia organizativa. No obstante, las valoraciones más negativas sobre la organización proceden de los desafiliados con contrato indefinido, que muestran su disconformidad con la acción del sindicato o de sus miembros, o con el funcionamiento y coste de los servicios sindicales. Entre ellos destacan por su mayor activismo sindical los que más tiempo han permanecido en el sindicato. En resumen, paradójicamente se observan más valoraciones positivas entre desafiliados periféricos, aunque tienen menos posibilidades de participar en la vida sindical y, en comparación, más valoraciones negativas entre desafiliados centrales, que cuentan con mayor libertad de elección.

Realizada esta descripción, y tomando como variable dependiente los motivos de desafiliación agrupados en dos categorías, los sindicales y los no sindicales (laborales $\mathrm{y}$, en mucha menor medida, familiares) - siendo esta última la referencia-, hemos efectuado una regresión logística que nos permita contrastar la hipótesis principal (ver tabla 5). En la dimensión personal, se constata que el sexo y el origen no son significativos en ninguno de los modelos, mientras que la edad pierde significación en la medida que introducimos nuevas variables; incluso el nivel de estudios, que en el modelo 1 es significativo -a mayor nivel de estudios se esgrimen más causas sindicales de desafiliación-, pierde su efecto en la medida que consideramos otros factores, entre ellos los institucionales. Las variables ocupacionales (modelo 2) se confirman como las más influyentes en los motivos de desafiliación. Así, los que pierden el empleo se decantan mucho más por razones no sindicales para explicar su desafiliación, aspecto que se acentúa más aún entre los que se jubilan o prejubilan; dichas razones, sobre todo las relacionadas con la situación de desocupación, también predominan entre los que trabajan o han trabajado en las empresas más pequeñas o en las que no hay afiliados; así como entre los desafiliados adscritos en su momento por protección ante la empresa y que confían en el sindicato (que les resuelve problemas) o en sus representantes. Una percepción más crítica del sindicato es propia de desafiliados con contrato estable, cualificados, que trabajan en empresas de mayor tamaño y con presencia del sindicato y son éstos los que aducen 
proporcionalmente más motivos sindicales como causa explicativa de la desafiliación. El modelo 3 (variables de afiliación) refuerza sobre todo el efecto de la situación laboral y del sector de actividad, mientras introduce nuevas consecuencias de orden institucional o de contexto, debidas al número de afiliados en la empresa; en cambio la presencia de CCOO en la empresa no adquiere ninguna asociación significativa. Por último el modelo 4 (participación sindical) muestra que el bajo compromiso sindical disminuye la propensión a desafiliarse por motivos no sindicales; mientras que la opinión regular o pésima sobre la organización (un indicador de insatisfacción) aumenta la propensión a dejar el sindicato por motivos sindicales.

Tabla 5. Resultados de la regresión logística, variable dependiente motivos de desafiliación (no sindicales vs sindicales)

\begin{tabular}{|c|c|c|c|c|c|c|c|c|c|}
\hline & \multicolumn{2}{|c|}{$\begin{array}{c}\text { Modelo 1: } \\
\text { variables } \\
\text { personales }\end{array}$} & \multicolumn{2}{|c|}{$\begin{array}{l}\text { Modelo 2: } \\
\text { variables } \\
\text { laborales } \\
\end{array}$} & \multicolumn{2}{|c|}{$\begin{array}{c}\text { Modelo 3: } \\
\text { variables de } \\
\text { afiliación } \\
\end{array}$} & \multicolumn{2}{|c|}{$\begin{array}{c}\text { Modelo 4: } \\
\text { variables de } \\
\text { participación }\end{array}$} \\
\hline & & $\operatorname{Exp}(B)$ & & $\operatorname{Exp}(B)$ & & $\operatorname{Exp}(B)$ & & $\operatorname{Exp}(B)$ & \\
\hline $\begin{array}{l}\text { Sexo Ref: } \\
\text { hombre }\end{array}$ & Hombre / Mujer & ,952 & & 1,259 & ns & 1,072 & & 1,075 & ns \\
\hline Edad & $\begin{array}{l}\text { De más joven a } \\
\text { más adulto } \\
\text { (años) }\end{array}$ & 988 & $* *$ & 1,016 & $*$ & 1,009 & ns & 1,011 & $\mathrm{~ns}$ \\
\hline $\begin{array}{l}\text { Nivel de } \\
\text { estudios } \\
\text { Ref: hasta } \\
\text { primaria }\end{array}$ & $\begin{array}{l}\text { Secundarios } \\
\text { FP sup, bachill, } \\
\text { BUP o COU } \\
\text { Universitarios }\end{array}$ & $\begin{array}{l}, 713 \\
, 521 * \\
, 362 *\end{array}$ & $\begin{array}{l}* * * \\
* * *\end{array}$ & $\begin{array}{l}, 890 \\
, 721 \\
, 622\end{array}$ & $\begin{array}{l}\text { ns } \\
\text { ns }\end{array}$ & $\begin{array}{l}, 994 \\
885 \\
, 820\end{array}$ & $\begin{array}{l}\mathrm{ns} \\
\mathrm{ns}\end{array}$ & $\begin{array}{l}\text {,959 } \\
860 \\
\text {,789 }\end{array}$ & \\
\hline $\begin{array}{l}\text { País de naci- } \\
\text { miento Ref: } \\
\text { España }\end{array}$ & & 1,221 & ns & 1,064 & ns & 874 & ns & 939, & $\mathrm{n}$ \\
\hline $\begin{array}{l}\text { Situación } \\
\text { laboral } \\
\text { Ref: Ocupado } \\
\text { indefinido }\end{array}$ & \begin{tabular}{|l|} 
Ocupado \\
temporal \\
Parado \\
Pensionista o \\
jubilado
\end{tabular} & & & $\begin{array}{r}1,187 \\
4,411 * \\
12,666 *\end{array}$ & \begin{tabular}{r|r}
$\mathrm{ns}$ \\
$* * *$ \\
$* * *$
\end{tabular} & $\begin{array}{r}1,448 \quad \text { I } \\
5,385 \quad * * \\
14,890 \quad * *\end{array}$ & $\begin{array}{r}\mathrm{ns} \\
k * * \\
k * *\end{array}$ & $\begin{array}{r}1,486 \quad \text { I } \\
5,481 \text { ** } \\
15,041 \quad \text { ** }\end{array}$ & $\begin{array}{r}\mathrm{ns} \\
* * * \\
* * *\end{array}$ \\
\hline $\begin{array}{l}\text { Antigüedad } \\
\text { trabajo } \\
\text { actual/anterior } \\
\text { Ref: }<2 \text { años }\end{array}$ & $\begin{array}{l}\text { De } 2 \text { a } 5 \text { años } \\
\text { Más de } 5 \text { años }\end{array}$ & & & $\begin{array}{l}, 604 \\
, 758 \\
\end{array}$ & $* *$ & ,583 & ns & ,600 & $* *$ \\
\hline $\begin{array}{l}\text { Categoría } \\
\text { profesional } \\
\text { Ref: Trabajador } \\
\text { poco cualifica- } \\
\text { do }\end{array}$ & \begin{tabular}{|l|} 
Trabajador \\
cualificado \\
Administrativo, \\
comercial, \\
servicios \\
Técnico o \\
profesional \\
Jefe o mando \\
intermed.
\end{tabular} & & & $\begin{array}{r}1,293 \\
, 808 \\
2,426\end{array}$ & $* *$ & $\begin{array}{r}1,212 \\
, 696 \\
2,135\end{array}$ & ns & $\begin{array}{r}1,259 \\
, 711 \\
2,150\end{array}$ & ns \\
\hline
\end{tabular}




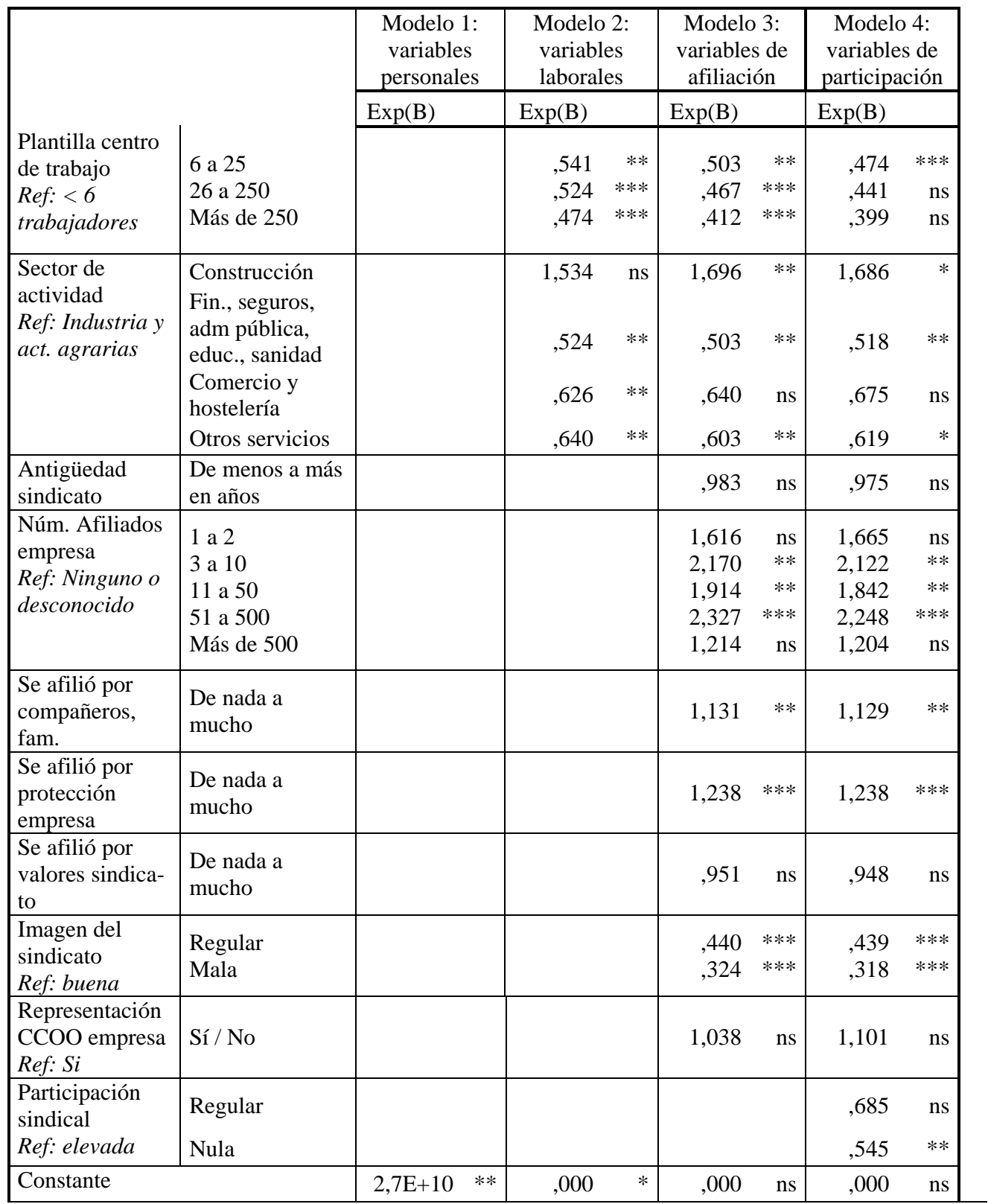

Nota: $* \mathrm{p} \leq 0,10 ; * * \mathrm{p} \leq 0,05 ; * * * \mathrm{p} \leq 0,01 ; \mathrm{ns}=$ no significativo

Resumen: $\quad 832$ casos en cada modelo
R2 Nagelkerke
0,051
0,279
0,365
0,370

Fuente: elaboración propia con datos de la encuesta CCOO a desafiliados/as 2009. 


\section{Una tipología de desafiliados}

Hasta aquí hemos abordado un análisis guiados por la hipótesis de que la situación laboral y la trayectoria afiliativa (afiliación, compromiso, permanencia) explican el momento y los motivos de la baja como miembro. En este sentido, la regresión logística confirma unas trayectorias sindicales de los afiliados centrales con una doble vertiente, permanencia hasta la jubilación (que es el motivo de la baja), o desafiliación tras una estancia media por insatisfacción con la organización; pero también aporta luz a las trayectorias de los afiliados periféricos cuya marcha, más cercana en el tiempo, está condicionada por la situación laboral; aunque no exclusivamente. El análisis de regresión logística, pero también las características relevantes de los desafiliados (esquema 2), nos invitó a formular una segunda hipótesis, mediante la cual esperamos que la combinación de trayectorias sindicales y motivaciones de salida permita ir más allá de la dualidad entre centrales y periféricos, configurando así una mayor segmentación entre los desafiliados. Para contrastarla, hemos recurrido a la técnica del análisis factorial de correspondencias múltiples a partir de la encuesta a desafiliados. En este análisis consideramos siete variables, que recogen diversos aspectos de la relación entre afiliado y compromiso sindical ${ }^{6}$; son las siguientes:

- Motivos de afiliación (más instrumentales, más no instrumentales, ambos, ninguno en particular);

- Número de afiliados al sindicato en la empresa;

- Existencia de representación sindical en la empresa;

- Imagen del sindicato (buena, regular, mala);

- Participación en actividades sindicales y responsabilidades organizativas (elevada, frecuente, poca, nula);

- Antigüedad en la afiliación sindical cuando se da de baja;

- Motivos de la baja (por pérdida o cambio de empleo, por jubilación o similar, no le ve utilidad, por desacuerdo con su funcionamiento, desacuerdo con la actuación de sus miembros, motivos personales, o se ha afiliado a otro sindicato).

El análisis factorial reduce las siete variables a unas pocas dimensiones, de las cuales la primera explica el 69,3\% de la varianza y la segunda un 14,9\%; es decir, entre ambas explican hasta el $84,2 \%$. La primera dimensión remite a contextos de afiliación favorables y desfavorables a la actividad y compromiso sindical: en un extremo se hallan quienes en su empresa cuentan con representación sindical, compañeros de trabajo afiliados, han participado en actividades sindicales y con antigüedad afiliativa, mientras en el otro están los que trabajan en empresas sin representación sindical, sin compañeros afiliados, sin participación en actividades

${ }^{6}$ Para más detalles sobre la elaboración del análisis factorial, ver Alós et al. (2011). A petición los autores facilitarán la confección del mismo y anexos correspondientes. 
sindicales y breves etapas en la organización. El segundo eje separa con base a la imagen del sindicato: en un extremo los afiliados con buena imagen del mismo y, en el otro, aquellos que no lo consideran necesario o muestran disconformidad con su acción.

A partir de las dimensiones generadas, el análisis de correspondencias múltiples permite dividir al conjunto de desafiliados en cinco grupos, cuyas características básicas se recogen en las tablas 6 y 7: la primera reproduce las siete variables definitorias de los grupos, mientras la segunda recoge sus principales rasgos personales y laborales. A continuación se comentan sus características básicas. Hay que advertir que hombres y mujeres se distribuyen por igual en todos los grupos (mujeres entre 33 y 37\%), su relación no es significativa. Recordemos que este análisis se refiere a desafiliados en los diez primeros meses de 2009, que coincide con una etapa de fuerte crisis económica y del empleo, que ha motivado un aumento significativo de las bajas sindicales. Por ello no puede dejar de considerarse que la dimensión de los grupos y su composición no son ajenos a ese contexto.

El primer grupo (25\% de la muestra) lo forman quienes acudieron al sindicato por motivos instrumentales; su estancia ha sido breve, como casi nula su participación; se desafilian por causas laborales y son poco críticos con la organización. Son jóvenes, casi la mitad en el paro y su último empleo radica en pequeñas empresas, sobre todo de la construcción, comercio y hostelería, empresas sin representación sindical y sin más afiliados. Pertenecen al segmento secundario del mercado de trabajo.

El segundo grupo (24\% de la muestra) lo integran afiliados por protección o por compañeros sindicalizados; mantienen buena imagen del sindicato y disponibilidad a volver a afiliarse, de resolverse los problemas laborales que motivaron su baja (pérdida del empleo). Tienen una permanencia corta en la organización y moderada participación colectiva. Son, sobre todo jóvenes en paro o con contrato temporal, de la construcción y comercio; por ello también asalariados periféricos.

El tercer grupo (12\% de la muestra) está formado por quienes trabajan en empresas con elevada presencia sindical, participación media en movilizaciones sindicales, pero sin responsabilidades; mantienen una imagen regular y desigual de la organización y mayor antigüedad organizativa que los grupos anteriores. Se desafilian por motivos sindicales o por no verle utilidad, y no piensan volver a afiliarse. Son trabajadores cualificados, con contrato indefinido, de los servicios más regulados, por tanto, del segmento primario del mercado de trabajo.

El cuarto grupo (15\% de los casos estudiados) incluye quienes trabajan en empresas con presencia sindical, edades avanzadas, con mucha antigüedad afiliativa y mayor activismo y asunción de responsabilidades. Tienen buena imagen de la organización, de la que se dan de baja por jubilación o similar. Son trabajadores con contrato indefinido, de empresas medianas o grandes, de la industria y algunos servicios públicos o sociales. Claramente son asalariados centrales.

El quinto grupo (24\% de la muestra) son asalariados afiliados con mayor incidencia proporcional de motivos no instrumentales. Trabajan en grandes empresas, con presencia sindical; cuentan con elevada antigüedad afiliativa y cierto compro- 
miso con la organización. Abandonan el sindicato por desacuerdo con algún responsable y guardan mala imagen del mismo. Empleo fijo y ocupación cualificada en servicios públicos o privados les convierten en asalariados centrales.

Tabla 6. Tipología de desafiliados y variables que la definen. Distribución para cada grupo (en \% por fila)

\begin{tabular}{|c|c|c|c|c|c|}
\hline & $\begin{array}{c}\text { Grupo } 1 \\
(25 \%)\end{array}$ & $\begin{array}{c}\text { Grupo } 2 \\
(24 \%)\end{array}$ & $\begin{array}{c}\text { Grupo } 3 \\
(12 \%)\end{array}$ & $\begin{array}{c}\text { Grupo } 4 \\
(15 \%)\end{array}$ & $\begin{array}{c}\text { Grupo } 5 \\
(24 \%)\end{array}$ \\
\hline \multicolumn{6}{|l|}{ Motivos afiliación: } \\
\hline Más instrumentales & 67,1 & 22,4 & 25,4 & 34,7 & 33,1 \\
\hline Más no instrumentales & 13,5 & 21,2 & 44,9 & 13,6 & 27,6 \\
\hline Ambos & 11,9 & 53,5 & 14,4 & 42,9 & 30,5 \\
\hline Ninguno en particular & 7,5 & 2,9 & 15,3 & 8,8 & 8,8 \\
\hline \multicolumn{6}{|l|}{ Núm. afiliados empresa: } \\
\hline Ninguno o desconocido & 70,1 & 28,7 & 16,1 & 32,4 & 35,6 \\
\hline Hasta 10 & 22,8 & 28,7 & 9,3 & 13,5 & 10,8 \\
\hline 11 a 50 & 2,0 & 24,2 & 4,2 & 17,6 & 8,8 \\
\hline 51 a 500 & 2,0 & 14,8 & 17,8 & 19,6 & 20,5 \\
\hline Más de 500 & 3,2 & 3,7 & 52,5 & 16,9 & 24,3 \\
\hline \multicolumn{6}{|l|}{ Representación CCOO empre- } \\
\hline Sí & 18,3 & 62,7 & 85,5 & 87,8 & 74,1 \\
\hline No & 81,7 & 37,3 & 14,5 & 12,2 & 25,9 \\
\hline \multicolumn{6}{|l|}{ Imagen sindicato $^{(1)}$ : } \\
\hline Buena & 21,1 & 43,7 & 20,3 & 47,6 & 2,9 \\
\hline Regular & 63,3 & 48,2 & 73,7 & 41,5 & 31,4 \\
\hline Mala & 14,3 & 7,3 & 5,1 & 10,2 & 64,9 \\
\hline \multicolumn{6}{|l|}{ Participación sindical: } \\
\hline Elevada & 1,6 & 6,6 & 1,7 & 54,4 & 9,2 \\
\hline Moderada & 4,3 & 20,1 & 37,3 & 19,7 & 26,9 \\
\hline Poca o nula & 94,0 & 73,4 & 61,1 & 25,8 & 63,9 \\
\hline \multicolumn{6}{|l|}{ Antigüedad en el sindicato: } \\
\hline Hasta 2 años & 57,5 & 57,6 & 25,2 & 4,7 & 25,5 \\
\hline Más de 2 hasta 5 & 28,6 & 26,9 & 53,8 & 23,1 & 17,1 \\
\hline Más de 5 años & 13,9 & 15,5 & 21,0 & 72,1 & 57,5 \\
\hline \multicolumn{6}{|l|}{ Motivo baja afiliación $^{(1)}$ : } \\
\hline Paro, cambio empresa & 25,9 & 85,2 & 11,9 & 17,0 & 13,0 \\
\hline Jubilación o similar & 1,2 & 0,8 & 7,6 & 47,6 & 2,1 \\
\hline No le ve utilidad & 40,2 & 7,8 & 26,3 & 6,8 & 6,7 \\
\hline Desacuerdo con actuación & 8,8 & 2,5 & 10,2 & 2,7 & 23,9 \\
\hline Desacuerdo funcionamiento & 7,2 & 1,6 & 5,1 & 8,2 & 51,7 \\
\hline Afiliado a otro sindicato & 0,0 & 0,0 & 38,1 & 0,0 & 0,0 \\
\hline Motivos personales & 14,3 & 1,2 & 0,0 & 15,0 & 0,4 \\
\hline
\end{tabular}

${ }^{(1)}$ Se han omitido las respuestas "ns/nc" o bien otras con valores residuales.

Nota: en negrita se resalta la sobrerrepresentación, en itálicas la subrepresentación.

Fuente: elaboración propia con base a la encuesta de desafiliados a CCOO, 2009. 
Tabla 7. Principales características personales y laborales de cada grupo de desafiliados

\begin{tabular}{|c|c|c|c|c|c|c|}
\hline & $\begin{array}{c}\text { Grupo } \\
1 \\
\end{array}$ & $\begin{array}{c}\text { Grupo } \\
2 \\
\end{array}$ & $\begin{array}{c}\text { Grupo } \\
3\end{array}$ & $\begin{array}{c}\text { Grupo } \\
4\end{array}$ & $\begin{array}{c}\text { Grupo } \\
5\end{array}$ & $\begin{array}{c}\text { V de } \\
\text { Cramer }\end{array}$ \\
\hline $\begin{array}{l}\text { Edad: } \\
\text { Hasta } 34 \text { años } \\
\text { De } 35 \text { a } 49 \\
50 \text { o más años }\end{array}$ & $\begin{array}{l}\mathbf{4 5 , 6} \\
39,3 \\
15,1 \\
\end{array}$ & $\begin{array}{l}46,7 \\
40,6 \\
12,7\end{array}$ & $\begin{array}{l}39,8 \\
43,2 \\
16,9\end{array}$ & $\begin{array}{c}7,5 \\
29,3 \\
63,3\end{array}$ & $\begin{array}{l}29,7 \\
\mathbf{4 6 , 9} \\
23,4\end{array}$ & $0,298 * *$ \\
\hline $\begin{array}{l}\text { Nivel de estudios } \\
\text { Hasta primarios } \\
\text { Secundarios } \\
\text { FP superior/bachiller. } \\
\text { Universitarios }\end{array}$ & $\begin{array}{l}26,1 \\
28,9 \\
27,7 \\
15,8\end{array}$ & $\begin{array}{l}26,5 \\
37,6 \\
24,5 \\
11,0\end{array}$ & $\begin{array}{l}14,4 \\
33,9 \\
28,0 \\
23,7\end{array}$ & $\begin{array}{l}26,5 \\
\mathbf{3 8 , 8} \\
23,8 \\
10,2\end{array}$ & $\begin{array}{l}18,8 \\
29,3 \\
28,9 \\
22,2\end{array}$ & $0,094 * *$ \\
\hline $\begin{array}{l}\text { Origen: } \\
\text { Español } \\
\text { Inmigrante }\end{array}$ & $\begin{array}{l}82,9 \\
17,1 \\
\end{array}$ & $\begin{array}{c}91,4 \\
8,6\end{array}$ & $\begin{array}{c}94,9 \\
5,1\end{array}$ & $\begin{array}{c}\mathbf{9 8 , 0} \\
2,0 \\
\end{array}$ & $\begin{array}{c}95,8 \\
4,2 \\
\end{array}$ & $0,200 * *$ \\
\hline $\begin{array}{l}\text { Situación laboral }^{(\mathbf{1})} \text { : } \\
\text { Con empleo fijo } \\
\text { Con empleo temporal } \\
\text { En paro } \\
\text { Pensionista/jubilado } \\
\end{array}$ & $\begin{array}{c}31,7 \\
17,9 \\
\mathbf{4 0 , 5} \\
5,2 \\
\end{array}$ & $\begin{array}{c}21,2 \\
18,8 \\
\mathbf{5 3 , 5} \\
2,9 \\
\end{array}$ & $\begin{array}{l}58,5 \\
14,4 \\
14,4 \\
11,0 \\
\end{array}$ & $\begin{array}{c}19,0 \\
3,4 \\
17,0 \\
\mathbf{5 5 , 8} \\
\end{array}$ & $\begin{array}{r}\mathbf{5 1 , 3} \\
13,9 \\
26,1 \\
7,1 \\
\end{array}$ & $0,311^{* *}$ \\
\hline $\begin{array}{l}\text { Antigüedad último empleo }{ }^{(\mathbf{1})} \text { : } \\
\text { Hasta } 2 \text { años } \\
\text { Más de } 2 \text { hasta } 5 \\
\text { Más de } 5 \text { años }\end{array}$ & $\begin{array}{l}47,8 \\
23,5 \\
23,9\end{array}$ & $\begin{array}{l}47,3 \\
19,2 \\
29,8 \\
\end{array}$ & $\begin{array}{l}20,3 \\
17,8 \\
\mathbf{6 0 , 2}\end{array}$ & $\begin{array}{r}8,2 \\
6,8 \\
\mathbf{8 0 , 3} \\
\end{array}$ & $\begin{array}{l}26,8 \\
25,9 \\
45,6\end{array}$ & $0,244^{* *}$ \\
\hline $\begin{array}{l}\text { N. empresas (5 últimos años) }{ }^{(\mathbf{1})} \text { : } \\
\text { Una } \\
\text { Dos } \\
\text { Tres o más }\end{array}$ & $\begin{array}{l}38,5 \\
\mathbf{2 8 , 2} \\
\mathbf{2 9 , 0}\end{array}$ & $\begin{array}{l}33,6 \\
30,3 \\
33,2\end{array}$ & $\begin{array}{l}\mathbf{6 8 , 4} \\
12,0 \\
19,7 \\
\end{array}$ & $\begin{array}{c}78,9 \\
9,5 \\
6,8 \\
\end{array}$ & $\begin{array}{l}54,4 \\
20,9 \\
21,8\end{array}$ & $0,198 * *$ \\
\hline $\begin{array}{l}\text { Categoría laboral última }{ }^{(\mathbf{1})} \text { : } \\
\text { Mando, profesional o técnico } \\
\text { Personal apoyo administrativo } \\
\text { Trabajador servicios } \\
\text { Oficial u operario } \\
\text { Trabajador no cualificado }\end{array}$ & $\begin{array}{c}13,5 \\
9,2 \\
19,5 \\
42,2 \\
12,4\end{array}$ & $\begin{array}{c}13,5 \\
7,8 \\
14,3 \\
\mathbf{4 4 , 7} \\
18,4\end{array}$ & $\begin{array}{l}23,7 \\
10,2 \\
16,1 \\
30,5 \\
15,3\end{array}$ & $\begin{array}{l}13,7 \\
12,3 \\
14,4 \\
41,1 \\
17,8\end{array}$ & $\begin{array}{l}23,5 \\
13,0 \\
16,8 \\
34,5 \\
11,8\end{array}$ & $0,103 * *$ \\
\hline $\begin{array}{l}\text { Plantilla empresa }^{(\mathbf{1})} \text { : } \\
\text { Hasta } 5 \text { trabajadores } \\
\text { De } 6 \text { a } 25 \\
\text { De } 26 \text { a } 250 \\
\text { Más de } 250\end{array}$ & $\begin{array}{c}26,3 \\
35,5 \\
23,5 \\
3,6\end{array}$ & $\begin{array}{l}18,0 \\
23,7 \\
37,6 \\
12,2\end{array}$ & $\begin{array}{c}5,1 \\
22,0 \\
37,3 \\
\mathbf{3 0 , 5}\end{array}$ & $\begin{array}{c}5,5 \\
21,9 \\
37,0 \\
\mathbf{3 0 , 1}\end{array}$ & $\begin{array}{l}10,4 \\
20,4 \\
36,3 \\
\mathbf{2 4 , 2}\end{array}$ & $0,183^{* *}$ \\
\hline $\begin{array}{l}\text { Sector de actividad }^{(\mathbf{1})} \text { : } \\
\text { Industria y agricultura } \\
\text { Construcción } \\
\text { Ent. financieras, seguros, adm. } \\
\text { públicas, educación, sanidad } \\
\text { Comercio y hostelería } \\
\text { Otros servicios } \\
\end{array}$ & $\begin{array}{l}14,3 \\
21,9 \\
12,0 \\
26,7 \\
23,1 \\
\end{array}$ & $\begin{array}{l}26,9 \\
\mathbf{2 0 , 8} \\
11,0 \\
19,2 \\
20,4 \\
\end{array}$ & $\begin{array}{c}20,2 \\
6,7 \\
\\
32,8 \\
10,9 \\
26,1 \\
\end{array}$ & $\begin{array}{c}33,6 \\
9,6 \\
\\
27,4 \\
10,3 \\
18,5 \\
\end{array}$ & $\begin{array}{c}21,9 \\
8,4 \\
\\
\mathbf{2 9 , 1} \\
13,9 \\
26,2 \\
\end{array}$ & $0,172 * *$ \\
\hline Volvería a afiliarse & $51,4 \%$ & $63,9 \%$ & $43,3 \%$ & $45,2 \%$ & $50,4 \%$ & $0,142^{* *}$ \\
\hline
\end{tabular}

(1) Se han omitido las respuestas "ns/nc" o bien otras con valores residuales.

* Asociación significativa al nivel 0,05; ** asociación significativa al nivel 0,01.

Nota: en negrita se resalta la sobrerrepresentación, en itálicas la subrepresentación.

Fuente: elaboración propia con base a la encuesta de desafiliados a CCOO, 2009. 


\section{Discusión y conclusiones: la teoría y la evidencia empírica contrastada en la trayectoria sindical de sus miembros}

Nuestro objetivo de estudio ha sido la trayectoria sindical, esto es la decisión de darse de alta en el sindicato, permanecer y comprometerse en su funcionamiento, o la baja del mismo. Para ello hemos iniciado el texto con un repaso a la literatura con el objeto de justificar el empleo por nuestra parte de una amplia gama de factores que influyen sobre la sindicalización. Seguidamente hemos comparado, para algunas variables, los datos de la ECVT, para todos los sindicatos con los del registro y la encuesta de CCOO; lo que nos ha permitido establecer en los apartados 6 (afiliados) y 7 (desafiliados) que la dinámica de este sindicato sigue una tendencia similar de puesta al día en la incorporación de trabajadores cualificados, con nivel de estudios medios y altos, del sector servicios, también en la afiliación de mujeres, jóvenes e inmigrantes; aunque éstos dos últimos con mucha fluctuación, acentuada por el lado de las bajas desde la actual crisis del empleo. También desde el punto de vista de la desafiliación se observa que tanto en la cifras ECVT, como en las de CCOO, las bajas se producen en segmentos primarios y en secundarios.

El repaso a la literatura especializada nos ha permitido exponer que la relación entre asalariados y organización no depende sólo de factores individuales e instrumentales (Olson, 1992; Klandermans, 1986); también hay vinculaciones organizativas, institucionales, o características individuales fruto de la socialización. El contexto empresarial y las oportunidades que abre el sindicato a la afiliación, se contrastan con las propensiones de los asalariados (Bain y Elsheikh, 1976) con base a sus expectativas y actitudes y a su experiencia laboral. En este sentido nuestros resultados se aproximan a Gallie (1996) o Waddington (2006), cuando remarcan que la menor afiliación de mujeres o jóvenes no se debe sólo a su pertenencia a un género o a una edad sino, sobre todo, a su mayor cercanía al trabajo atípico y la precariedad.

La justificación teórica, además, nos ha permitido trazar la hipótesis según la cual la trayectoria sindical (afiliación, compromiso, permanencia) se relaciona con la situación de empleo (asalariados centrales y periféricos), de manera que la interacción entre ambas explica los motivos de desafiliación. Por su lado, una regresión logística, cuya variable dependiente es el motivo de la baja (tomando como referencia las motivaciones no sindicales), confirma que la situación ocupacional es el factor más influyente; pero sin descuidar la trayectoria sindical. Así, entre los asalariados centrales se observan relaciones entre largas permanencias y alto compromiso con el sindicato, unidas a la baja por jubilación y, también, medias o largas permanencias en el sindicato, asociadas con menor compromiso y bajas por insatisfacción con la organización. Y, entre los asalariados periféricos se observan principalmente relaciones entre trayectorias cortas, compromiso organizativo reducido y motivos laborales de desafiliación.

Es decir, incorporar la trayectoria sindical permite constatar que hay un cierto vínculo de continuidad entre la decisión de afiliarse al sindicato, junto a las motivaciones que conducen a la misma, y el tiempo de permanencia hasta la baja definitiva, 
producida por unas u otras causas (sindicales o laborales). De manera que la contrastación de nuestra hipótesis principal con los datos aporta evidencias: primero, de que la segmentación en el mercado de trabajo se reproduce, aunque no necesariamente de forma simétrica, en la organización sindical; segundo, que la diversidad de trayectorias sindicales se debe no sólo a factores internos a los sindicatos, sino también del contexto institucional y, sobre todo, económico y empresarial (Newton y Shore, 1992; Gallagher y Clark, 2001). Tercero, que las motivaciones de desafiliación están asociadas con la trayectoria sindical y la situación ocupacional (Guest y Conway, 2004; Cregan, 2005).

La dualidad inicialmente planteada en la hipótesis principal se matiza con el análisis de regresión logística, en el que aparecen nuevas distinciones. La segunda hipótesis presupone que la introducción del conjunto de variables presente en el esquema 1, pudiera inducir una segmentación más acusada. Para contrastarla, utilizamos la combinación del análisis factorial con el de correspondencias múltiples para detectar los diferentes tipos de desafiliados (con paralelismos respecto de Cregan, 2005). El análisis factorial revela que la dimensión contextual explica un $70 \%$ de la varianza, mientras que la dimensión de actitud individual sólo explica el 14\%. Así, tomando como ejemplo a los afiliados o desafiliados pertenecientes al segmento laboral secundario, sus dificultades de acceso al sindicato son de orden diverso: la inestabilidad o precariedad laboral, su ocupación en sectores y pequeñas empresas que diseñan puestos de trabajo de baja cualificación y salario, sin representación de los trabajadores, ni cobertura de la negociación colectiva. Dichas condiciones se corresponden con su adscripción puntual e instrumental al sindicato; por ejemplo, la protección o resolución de un problema laboral grave. Ello conduce a una permanencia breve, en la que no hay tiempo, ni espacio, para el compromiso y la participación. No obstante, en los casos en que la urgencia y la gravedad no es tan elevada y en los paréntesis de estabilidad laboral, también cuando hay afinidad (compañeros afiliados, pongamos por caso) o identificación, la permanencia se amplia y el compromiso es mayor; ello se manifiesta en una opinión de simpatía hacia el sindicato, o hacia la participación en la acción colectiva y, en caso de baja, en la disponibilidad a volver a afiliarse una vez solucionados los problemas que les condujo a la misma (casi siempre razones laborales, no sindicales).

Esta combinación de técnicas ha permitido, asimismo, identificar cinco tipos de trayectorias sindicales, asociadas a colectivos con características propias destacadas tanto a nivel personal como, y, sobre todo, laboral (esquema 3). Así, en cuanto a los motivos de aproximación y adscripción al sindicato debe matizarse nuestro supuesto de partida, en el sentido de que, si bien globalmente se confirma que los trabajadores centrales se decantan más por apreciar los aspectos no instrumentales de afiliación (valores y socialización) y los trabajadores periféricos por los instrumentales, en cada segmento se reconocen diferencias significativas. En este sentido destaca el grupo 2, de trabajadores periféricos, cuyo compromiso sindical no puede considerarse meramente instrumental y que, además, manifiesta que volvería a afiliarse en caso de resolverse los problemas laborales que le condujeron a la baja. Las diferencias son evidentes también en términos de participación, destacando en 
un extremo quienes acceden a la prejubilación o jubilación por su mayor confianza en el sindicato, que se refleja en sus niveles de implicación con la organización; en el otro extremo se sitúan los trabajadores periféricos del grupo 1, que se adhieren al sindicato puntualmente, sobre todo para resolver algún problema laboral. En ambos grupos (1 y 2) hay mayor presencia de jóvenes cuya incorporación o baja depende, en gran medida, de la situación de empleo, lo que coincide con Waddington y Kerr (2002); también en el grupo 1 de inmigrantes cuyas relaciones con el sindicato dependen de su situación de empleo (Turner et al, 2007). Todo ello se refleja en el tiempo de permanencia en la organización, más elevada para los primeros, más breve para los segundos; una diferencia intergeneracional, también remarcada por Haynes (2005). Los motivos de desafiliación reproducen esencialmente los planteados en el apartado de resultados, aunque ahora los podemos identificar con grupos específicos de desafiliados, al mismo tiempo que se reconoce el grupo 3 , de trabajadores centrales, que destacan por manifestar que no encuentran utilidad al hecho de estar afiliado y que no volverían a afiliarse, incluso en el caso de resolverse sus diferencias con el sindicato (Cregan, 2005; Waddington, 2006).

Esquema 3. Tipología de trayectorias sindicales

\begin{tabular}{|l|l|l|l|l|l|}
\hline & $\begin{array}{c}\text { Motivo afilia- } \\
\text { ción }\end{array}$ & $\begin{array}{l}\text { Compromiso } \\
\text { sindical }\end{array}$ & $\begin{array}{l}\text { Permanencia } \\
\text { en la organi- } \\
\text { zación }\end{array}$ & Desafiliación & \multicolumn{1}{|c|}{$\begin{array}{c}\text { Imagen } \\
\text { del } \\
\text { sindicato }\end{array}$} \\
\hline $\begin{array}{l}\text { Grupo 1 } \\
\text { (periféricos) }\end{array}$ & $\begin{array}{l}\text { Más instrumen- } \\
\text { tales }\end{array}$ & Nulo & Muy breve & No le ve utilidad & Regular \\
\hline $\begin{array}{l}\text { Grupo 2 } \\
\text { (periféricos) }\end{array}$ & Ambos & Escaso & Breve & $\begin{array}{l}\text { Paro, cambio } \\
\text { empresa }\end{array}$ & Buena \\
\hline $\begin{array}{l}\text { Grupo 3 } \\
\text { (centrales) }\end{array}$ & $\begin{array}{l}\text { Más no instru- } \\
\text { mentales o } \\
\text { ninguno en } \\
\text { especial }\end{array}$ & Moderado & Media & $\begin{array}{l}\text { No le ve utilidad / } \\
\text { Afiliado a otro } \\
\text { sindicato }\end{array}$ & Regular \\
\hline $\begin{array}{l}\text { Grupo 4 } \\
\text { (centrales) }\end{array}$ & Ambos & Elevado & Muy elevada & $\begin{array}{l}\text { Jubilación o } \\
\text { similar / Motivos } \\
\text { personales }\end{array}$ & Buena \\
\hline $\begin{array}{l}\text { Grupo 5 } \\
\text { (centrales) }\end{array}$ & $\begin{array}{l}\text { No instrumen- } \\
\text { tales o ninguno }\end{array}$ & Moderado & Elevada & $\begin{array}{l}\text { Desacuerdo con } \\
\text { organización o } \\
\text { representantes }\end{array}$ & Mala \\
\hline
\end{tabular}

Fuente: elaboración propia.

Otra conclusión es que los grupos descritos configuran una organización diversa y plural, alejada de la imagen monolítica y oligopólica que se le atribuye desde ciertas perspectivas; una organización que, indudablemente, se enfrenta a un panorama complejo en el que la renovación de los instrumentos orgánicos, como muestran Oesch (2012), Pedersini (2010), Heery et al. (2000), es crucial. Por una parte, debe retener ese $15 \%$ aproximado de afiliados que se jubilan y que durante su militancia han sido un sostén importante del sindicato. Atender las razones específicas de los que se distancian de la organización (y se dan de baja) por discrepancias ideológicas 
y por desacuerdo con sus representantes (grupo 5) sería otro aspecto a desarrollar, dada su importancia, al menos en términos numéricos. Sin olvidar otro colectivo de trabajadores fijos (grupo 3), cuyo alejamiento de la organización, tras algunos años de afiliación, argumentan en la escasa utilidad del sindicato. Finalmente, restan los dos grupos de trabajadores periféricos, temporales y que han perdido el empleo; ambos grupos representan cerca de la mitad de la desafiliación. Buen servicio y buen trato, proximidad (las estrategias de organización y de servicio que promocionan los sindicatos anglosajones) parecen dar resultado en estos segmentos. Ciertamente, a unos (grupo 2) las circunstancias laborales les puede llevar a dejar la organización, mientras otros (grupo 1) la abandonan por no verle utilidad, más allá del asesoramiento puntual; aunque no puede olvidarse que ambos colectivos muestran unos niveles medios o elevados de simpatía hacia la organización que les ha atendido en sus demandas, por lo que representan un entorno "simpatizante" que el sindicato debe considerar.

También queremos dejar constancia que los resultados obtenidos cuestionan los planteamientos de autores y organizaciones que sostienen que los sindicatos no sólo descuidan los intereses de los trabajadores jóvenes con contrato temporal, sino que generan la dualización del mercado de trabajo, al defender los intereses de los trabajadores centrales frente a los periféricos. La complejidad de la composición de los sindicatos y de las trayectorias sindicales observadas va más allá de lecturas simples, ideológicas e interesadas. Hay segmentos de trabajadores que, al margen del sindicato, por sí solos tienen capacidad negociadora. Para ellos afiliarse es un recurso que aumenta sus oportunidades; si las expectativas no se cumplen, la búsqueda de la utilidad les conduce a desafiliarse, o a afiliarse a otro sindicato. Y hay grupos de trabajadores en la periferia del sistema, que también recurren al sindicato, cuando les es posible o lo necesitan; aunque la precariedad de sus condiciones laborales, dificulta la acción sindical en su favor. Y, no obstante, una parte sustancial de la renovación anual del sindicato se hace a partir de este tipo de trabajadores. Dejan la organización en mayor medida que los centrales, impelidos por circunstancias laborales poco favorables; sin embargo, algunos de ellos valoran positivamente la acción sindical. Sin duda, sobre estos asalariados periféricos debe recaer una acción sindical firme de acompañamiento y estímulo a la permanencia.

Una limitación importante del estudio presentado es el análisis de las bajas del sindicato en el año 2009, caracterizado por la fuerte crisis económica. Esta limitación nos lleva a plantear la conveniencia de validar los resultados obtenidos en el futuro; comparar los dos momentos del ciclo económico puede resultar particularmente interesante. Creemos conveniente, además, continuar la investigación de trayectorias sindicales usando datos longitudinales y las metodologías que se adecuan a su análisis; ello permitiría entrelazar el estatus orgánico de un individuo, con la duración de su afiliación, también con su trayectoria sindical en el tiempo, relacionada con sus características personales o con las de la empresa en la que trabaja. Asimismo, sería de mucho interés ampliar el análisis al conjunto de la afiliación sindical en España, distinguida al menos por los grandes sindicatos, así como su comparación con países de nuestro entorno; ello depende de acceder a fuentes de 
datos, hoy por hoy, inexistentes en nuestro país. Esta es una asignatura pendiente en la que en los años en que llevamos de democracia apenas se ha avanzado.

\section{Bibliografía}

Allvin, M.; Sverke, M. (2000): "Do New Generations imply the End of Solidarity? Swedish Unionism in the Era of Individualization" Economic and Industrial Democracy, 21, 1: 71-95.

Alós, R.; Jódar, P.; Martí, J.; Martín, A.; Miguélez, F.; Rebollo, O. (2000): La transformación del sindicato: estudio de la afiliación de CCOO de Cataluña, Barcelona, Viena.

Alós, R. (2008): "Segmentación de los mercados de trabajo y relaciones laborales. El sindicalismo ante la acción colectiva” Cuadernos de relaciones laborales, 26,1: 123-148.

Alós, R.; Beneyto, P.; Jódar, P.; Vidal, S. (2011): La dinámica de la afiliación sindical. El caso de Comisiones Obreras, Madrid, Fundación $1^{\circ}$ de Mayo.

Antón, A. (2007): "Sindicatos y jóvenes: el reto de sus vínculos”, Mientras Tanto, 103: 45-63.

Bain, G.S.; Elsheikh, F. (1976): Union Growth and the Business Cycle. An Econometric Analysis, Oxford, Basil Blackwell.

Banyuls, J.; Miguélez, F.; Recio, A.; Cano, E. (2009): "The Transformation of the Employment System in Spain: Towards a Mediterranean Neoliberalism?”, en G. Bosch, S. Lehndorff y J. Rubery (eds.), European Employment in Flux. A Comparison of Institutional Change in Nine European Countries, Houndmills, Palgrave Macmillan.

Barling, J.; Fullagar, C.; Kelloway, E.K. (1992): The Union and Its Members: A Psychological approach, Cary, Oxford Univ Press.

Baylos, A. (1999): "La intervención normativa del Estado en las relaciones laborales colectivas”, en F. Miguélez y C. Prieto (coords.), Las relaciones de empleo en España, Madrid, Siglo XXI.

Beneyto, P.J. (2004): "La afiliación sindical en España: viejos tópicos y nuevas realidades”, en P.J. Beneyto (ed.), Afiliación sindical en Europa. Modelos y estrategias, Alzira, Germania.

Beneyto, P.J. (2008): "El sindicalismo español en perspectiva europea: de la anomalía a la convergencia” Cuadernos de Relaciones Laborales, 26, 1: 57-88.

Beneyto, P.J. (2011a): "Fortalezas y debilidades del sistema español de representación sindical” Gaceta Sindical. Reflexión y debate, 16: 195-223.

Beneyto, P.J. (2011b): “Sindicatos, relaciones laborales y gestión de RRHH”, en M. González Menéndez, R. Gutiérrez Palacios y M. Martínez Lucio (coords.), Gestión de Recursos Humanos: Contexto y Políticas, Cizur Menor, Aranzadi.

Blackwood, L.; Lafferty, G.; Duck, J.; Terry, D. (2003): "Putting the Group Back into Unions: A Social Psychological Contribution to Understanding Union Support” The Journal of Industrial Relations, 45, 4: 485-504. 
Blanchflower, D.G. (2007): “International Patterns of Union Membership” British Journal of Industrial Relations, 45, 1: 1-28.

Booth, A.; Burda, M.; Calmfors, L.; Checchi, D.; Naylor, R.; Visser, J. (2000): What do Unions do in Europe? Prospect and Challenges for Union Presence and Union Influence, Milano, Fondazione Rodolfo Debenedetti.

Brady, D. (2007): "Institutional, Economic or Solidaristic? Assessing Explanations for Unionization Across Affluent Democraties” Work and Occupations, 14, 1: 67-101.

Bryson, A.; Gomez, R. (2005): "Why Have Workers Stopped Joining Unions? The Rise in Never-Membership in Britain” British Journal of Industrial Relations, 43, 1: 67-92.

Calderón, J.A.; López Calle, P. (2010): “Transformaciones del trabajo e individualización de las relaciones laborales. La emergencia de nuevas formas de resistencia en el trabajo" Sociología del Trabajo, 68: 3-26.

Calmfors, L.; Booth, A.; Burda, M.; Checchi, D.; Naylor, R.; Visser, J. (2002): "Il futuro della contrattzazione collettiva in Europa”, en T. Boeri, A. Brugiavini y L. Calmfors (eds.), Il ruolo del sindacato in Europa, Milano, Università Bocconi.

Checchi, D.; Lucifora, C. (2002): "Union density. The economic roles of unions and institutions" Economic Policy, 17, 35: 361-408.

Checchi, D.; Visser, J. (2005): "Pattern Persistence in European Trade Union Density. A longitudinal analysis 1950-1996” European Sociological Review, 21, 1: $1-21$.

Checchi, D.; Visser, J.; van de Werfhorst, H.G. (2010): "Inequality and Union Membership: The Influence of Relative Earnings and Inequality Attitudes" British Journal of Industrial Relations, 48, 1: 84-108.

Cregan, C. (2005): “Can Organizing Work? An Inductive Análisis of Individual Attitudes Toward Union Membership” Industrial and Labor Relations Review, 58, 2: 282-304.

Doeringer, P.B.; Piore, M.J. (1983); "Los mercados internos de trabajo", en L. Toharia (comp.), El mercado de trabajo: teoría y aplicaciones, Madrid, Alianza Universidad.

Dolado, J.J.; Felgueroso, F.; Jansen, M. (2010): El conflicto entre la demanda de flexibilidad laboral y la resistencia a la reforma del mercado de trabajo en España, Madrid, FEDEA.

Dubois, P. (1976): Le sabotage dans l'industrie, Paris, Calmann-Levy.

Ebbinghaus, B.; Visser, J. (1998): "When Institutions Matter: Union Growth and Decline in Western Europe, 1950-95” Working Paper I/30, Mannheim, MZES.

Fernández Macías, E. (2002): “Tipo de contrato y actitudes hacia los sindicatos”, en A. García y W. Sanguinetti (eds.), Sindicatos y cambios económicos y sociales, Salamanca, Universidad de Salamanca.

Ferner, A.; Hyman, R. (1998): "Introduction: Towards European Industrial Relations?”, en A. Ferner y R. Hyman (eds.), Changing industrial relations in Europe, Oxford, Blackwell Publishers.

Freeman, R.B.; Medoff, J.L. (1984): What Do Union Do?, New York, Basic Books. 
Friedman, B.A.; Abraham, S.E.; Thomas, R.K. (2006): "Factors Related to Employees' Desire to join and Leave Unions” Industrial Relations, 45, 1: 102-110.

Gallagher, D.G.; Clark, P.F. (2001): "Research on Union Commitment: Implications for Labor” Labor Studies Journal, 14, 1: 52-71.

Gallie, D. (1996): "Skill, Gender and the Quality of Employment”, en R. Crompton, D. Gallie y K. Purcell (eds.), Changing Forms of Employment. Organisations, skills and gender, London, Routledge.

Germe, J.F. (2011): "Projet professional et incertitude dans sur le marché du travail” Papers. Revista de sociologia, 96, 4: 1125-1138.

Gomez, R.; Gunderson, M.; Meltz, N.M. (2004): "From Playstations to Workstations: Young Workers and the Experience-Good Model of Union Membership”, en A. Verma y T.A. Kochan (eds.), Unions in the 21st Century. An International Perspective, New York, Palgrave Macmillan.

Guest, D.E.; Dewe, P. (1988): "Why Do Workers Belong to a Trade Union?: A Social Psychological Study in the UK Electronics Industry" British Journal of Industrial Relations, 26, 2: 178-194.

Guest, D.E.; Conway, N. (2004): "Exploring the paradox of unionised worker dissatisfaction” Industrial Relations Journal, 35, 2: 102-120.

Haynes, P.; Vowles, J.; Boxall, P. (2005): "Explaining the Younger-Older Worker Union Density Gap: Evidence From New Zealand” British Journal of Industrial Relations, 43, 1: 93-116.

Heery, E.; Simms, M.; Delbridge, R. Salmon, J; Simpson, D. (2000) "Union organizing in Britain: a survey of policy and practice". Int. J. of Human Resource Management, 11, 5: 986-1007.

Hyman, R. (1994): "Industrial Relations in Western Europe: An Era of Ambiguity?”, Industrial Relations, 33, 1: 1-24.

Hyman, R. (2004): "The Future of Trade Unions", en A. Verma y T.A. Kochan (eds.), Unions in the $21^{\text {st }}$ Century. An Internationale Perspective, New York, Palgrave Macmillan.

Jódar, P.; Alós, R.; Vidal, S.; Ortiz, L.; Garrell, D. (2009a): La diversitat en el sindicat. Trets demogràfics i ocupacionals, valors i participación de l'afiliació a CCOO de Catalunya, Barcelona, CERES.

Jódar, P.; Alós, R.; Vidal, S. (2009b): "Por qué los afiliados al sindicato se dan de baja. Un estudio de la desafiliación de CCOO de Cataluña” Sociología del trabajo, 65: 31-52.

Jódar, P.; Vidal, S.; Alós, R. (2011a): "Union Activism in an Inclusive System of Industrial Relations: Evidence from a Spanish Case Study” British Journal of Industrial Relations, 49, S1: 158-180.

Jódar, P.; Alós, R.; Vidal, S. (2011b): "Why do workers leave unions? Group differences between workers in CCOO-Catalonia” Transfer. European Review of Labour and Research, 17, 4: 471-484.

Jódar, P.; Alós, R.; Boso, À.; Guiu, J. (2011c): L’afiliació esrtrangera a CCOO de Catalunya, Barcelona, CERES. 
Jordana, J. (1996): "Reconsidering Union Membership in Spain, 1977-1994: Halting Decline in a Context of Democratic Consolidation” Industrial Relations Journal, 27, 3: 211-224.

Kirton, G. (2005): “The influences on women joining and participating in unions” Industrial Relations Journal, 36, 5: 386-401.

Klandermans, B. (1986): "Psychology and trade union participation: Joining, acting, quitting” Journal of Occupational Psychology, 59: 189-204.

Klandermans, B. (2002): "How group identification helps to overcome the dilemma of collective action" American Behavioral Scientist, 45, 5: 887-900.

Kochan, T.A.; Katz, H.C.; McKersie, R.B. (1993): Las transformaciones de las relaciones laborales en los Estados Unidos, Madrid, Ministerio de Trabajo y Seguridad Social.

Köhler, H.D.; Calleja, J.P. (2011): "Retos de futuro para las organizaciones sindicales en España” Gaceta Sindical. Reflexión y debate, 16: 119-138.

Kuruvilla, S.; Gallagher, D.S.; Fiorito, J.; Wakabayashi, M. (1990): "Union participation in Japan: do Western theories apply?” Industrial and Labor Relations Review, 43, 4: 374-389.

Labbé, D.; Croisat, M. (1992): La fin des syndicats?, Paris, L'Harmattan.

Lange, P.; Ross, G. (1991): "Conclusiones: evolución de los sindicatos franceses e italianos en el marco de una perspectiva comparada”, en P. Lange, G. Ross y M. Vannicelli (eds.), Sindicato, cambio y crisis: la estrategia sindical en Francia y en Italia y la economía política de 1945 a 1980, Madrid, Ministerio de Trabajo y Seguridad Social.

Lévesque, C.; Murray, G.; Le Queux, S. (2005): "Union Disaffection and Social Identity. Democracy as a Source of Union Revitalization” Work and Occupations, 32, 4: 400-422.

Llorente Sánchez, D. (2007): "Explaining union membership of temporary workers in Spain: the role of local representatives and workers' participative potential" Industrial Relations Journal, 38, 1: 51-69.

Lorenz, D.; Valeyre, A. (2005): “Organisational Innovation, Human Resource Management and Labour Market Structure. A Comparison of the EU-15" The Journal of Industrial Relations, 47, 4: 424-442.

Miguélez, F. (1999): "Presente y futuro del sindicalismo en España”, en F. Miguélez y C. Prieto (coords.), Las relaciones de empleo en España, Madrid, Siglo XXI.

Miguélez, F.; Recio, A. (2009): Life course in Spain, Dynamic of National Models of Employment (DYNAMO), Working Paper, Essen, Institute for Work, Skills and Training, University of Duisburg.

Newton, L.A.; Shore, L.M. (1992): “A Model of Union Membership: Instrumentality, Commitment, and Opposition” Academy of Management Review, 17, 2: 275298.

Oesch, D. (2012): "Recruitment, Retention and Exit from Union Membership. An Analysis of Member Flows in Swiss Union Locals”, British Journal of Industrial Relations (pendiente de publicación). 
Olson, M,.(1992): La lógica de la acción colectiva. México: Limusa Noriega Editores.

Pedersini, R. (2010)Trade union strategies to recruit new groups of workers. Dublín,EUROFOUND.

http://www.eurofound.europa.eu/docs/eiro/tn0901028s/tn0901028s.pdf

Piore, M.J. (1983): "Los fundamentos tecnológicos del dualismo y de la discontinuidad”, en L. Toharia (comp.), El mercado de trabajo: teorías y aplicaciones, Madrid, Alianza.

Prieto, C.; Arnal, M.; Caprile, M. (2009): La calidad del empleo en España: una aproximación teórica y empírica, Madrid, Ministerio de Trabajo e Inmigración.

Recio, A. (1999): "La segmentación del mercado laboral en España”, en F. Miguélez y C. Prieto (coords.), Las relaciones de empleo en España, Madrid, Siglo XXI.

Recio, A. (2005): “Notas sobre el modelo de empleo español” Gaceta Sindical. Reflexión y debate, 5: 77-100.

Rodríguez Gutiérrez, C. (1996): "Determinantes de la afiliación sindical en España”, Moneda y Crédito, 201: 149-174.

Schnabel, C. (2003): "Determinants of trade unions membership", en J.T. Addison y C. Schnabel (eds.), International Handbook of Trade Unions, Cheltenham, Edward Elgar.

Schnabel, C.; Wagner, J. (2007): "Union density and determinants of union membership in 18 EU countries: evidence from micro data, 2002/03" Industrial Relations Journal, 38, 1: 5-32.

Scruggs, L.; Lange, P. (2001): "Unemployment and union density", en N. Bormeo (ed.), Unemployment in the New Europe, Cambridge, Cambridge University Press.

Simón, H.J. (2003): "Qué determina la afiliación a los sindicatos en España?” Revista del Ministerio de Trabajo y Asuntos Sociales, 41: 69-41. [en www.empleo.gob.es/es/publica/pub_electronicas/destacadas/revista/numeros/41/ est4.pdf]

Sinclair, D.M. (1996): "The importance of gender for participation in and attitudes to trade unionism”, Industrial Relations Journal, 27, 3: 239-52.

Sudano, L. (1998): "Women union leaders: mongrels, martyrs, misfits or models for the future?”, en B. Pocock (ed.), Strife, Sex and Politics in Labour Unions, St Leonards, Allen and Unwin.

Toharia, L. (2011): "El debate sobre las reformas necesarias para la economía española: el mercado de trabajo” Gaceta Sindical. Reflexión y debate, 17: 201236.

Tomlinson, J. (2005): "Women's attitudes towards trade unions in the UK: a consideration of the distinction between full- and part-time workers" Industrial Relations Journal, 36, 5: 402-418.

Turner, T.; D’Art, D.; y O'Sullivan, M. (2007): “Union availability, union membership and immigrant workers. An empirical investigation of the Irish case”. Employee Relations, 30, 5: 479-493 
Valdés Dal-Ré, F. (1996): Relaciones laborales, negociación colectiva y pluralismo social, Madrid, Ministerio de Trabajo y Seguridad Social.

Visser, J. (1995): “Trade unions from a comparative perspective”, en J. Van Ruysseveldt, R. Huiskamp y J. van Hoof (eds.), Comparative Industrial \& Employment Relations, London, SAGE Publications.

Visser, J. (2002): "Why Fewer Workers Join Unions in Europe: A Social Custom Explanation of Membership Trends" British Journal of Industrial Relations, 4, 3: 403-430.

Waddington, J.; Kerr, A. (1999): “Trying to stem de flow: Union membership turnover in the public sector" Industrial Relations Journal, 30, 3: 184-196.

Waddington, J.; Kerr, A. (2002): “Unions fit for young workers?” Industrial Relations Journal, 33, 4: 298-315.

Waddington, J. (2006): "Why Do Members Leave? The Importance of Retention to Trade Union Growth” Labor Studies Journal, 31, 3: 15-38.

Western, B. (1997): Between Class and Market. Postwar Unionization in the Capitalist Democracies, Princeton, Princeton University Press.

Wrench, J. (2004): “Trade Union Responses to Immigrants and Ethnic Inequality in Denmark and the UK: the Context of Consensus and Conflict”. European Journal of Industrial Relations, 10 (1), pp. 7-30. 